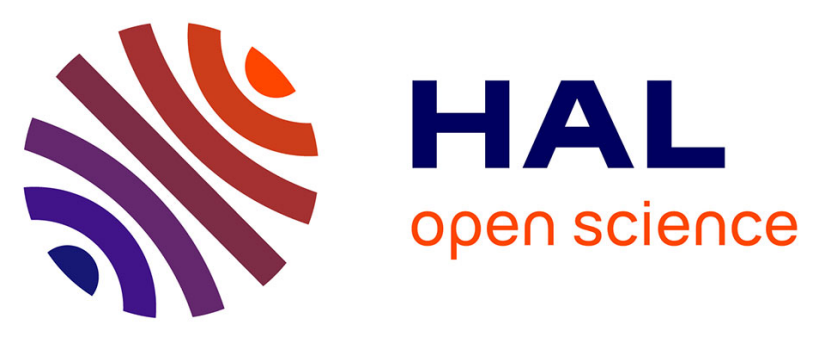

\title{
Detection and evaluation of barely visible impact damage in woven glass fabric reinforced polyamide 6.6/6 composite using ultrasonic imaging, X-ray tomography and optical profilometry
}

Nada Miqoi, Pascal Pomarede, Fodil Meraghni, Nico Felicien Declercq, Laurent Guillaumat, Gael Le Coz, Stéphane Delalande

\section{To cite this version:}

Nada Miqoi, Pascal Pomarede, Fodil Meraghni, Nico Felicien Declercq, Laurent Guillaumat, et al.. Detection and evaluation of barely visible impact damage in woven glass fabric reinforced polyamide 6.6/6 composite using ultrasonic imaging, X-ray tomography and optical profilometry. International Journal of Damage Mechanics, 2020, 10.1177/1056789520957703 . hal-02965886

\author{
HAL Id: hal-02965886 \\ https://hal.science/hal-02965886
}

Submitted on 13 Oct 2020

HAL is a multi-disciplinary open access archive for the deposit and dissemination of scientific research documents, whether they are published or not. The documents may come from teaching and research institutions in France or abroad, or from public or private research centers.
L'archive ouverte pluridisciplinaire HAL, est destinée au dépôt et à la diffusion de documents scientifiques de niveau recherche, publiés ou non, émanant des établissements d'enseignement et de recherche français ou étrangers, des laboratoires publics ou privés. 


\title{
Detection and evaluation of barely visible impact damage in woven glass fabric reinforced polyamide 6.6/6 composite using ultrasonic imaging, X-ray tomography and optical profilometry
}

\author{
N Miqoi 1,2,3, P Pomarede², F Meraghni' (D, \\ NF Declercq ${ }^{2}$, L Guillaumat ${ }^{4}, \mathbf{G}$ Le Coz' and \\ S Delalande ${ }^{3}$
}

\begin{abstract}
The present experimental work investigates the response of woven glass fabric reinforced polyamide 6.6/ 6 subjected to drop weight impact loading. The main objective is the development and the introduction of a new experimental procedure/approach, based on different complementary detection techniques, that aims at investigating the damage induced by impact loading in thermoplastic woven fabric composites. The developed approach is intended to be generalized to other types of composite materials. The main idea is to assess all the experimental results obtained through the developed procedure with a direct investigation method. The latter consists in the Permanent Indentation (PI) measurement providing an indicator of the damage criticality in the composite sample. To this end, several non-destructive testing methods are carried-out and their experimental findings are analyzed and cross-linked. The identification of the different damage mechanisms, caused by the drop weight impact, is performed using X-Ray microcomputed tomography $(\mu \mathrm{CT})$. C-scan ultrasonic investigation is conducted according to two types: transmission and reflection for the detection of the impact damage and the identification of the induced degradation area. B-scan imaging are then obtained through specific post-processing of the impacted surface to extract the permanent indentation (PI). The latter is validated through surface flatness measurement using the highly resolved 3D optical profilometry. The correlation between the X-Ray tomography results and the permanent indentation measurement is then established. It correlates the PI level
\end{abstract}

\footnotetext{
'Arts et Métiers Institute of Technology, CNRS, Université de Lorraine, Metz, France

${ }^{2}$ Georgia Tech-UMI 2958 CNRS, Metz, France

${ }^{3}$ PSA Group - Centre technique de Vélizy A, Vélizy-Villacoublay, France

${ }^{4}$ Arts et Métiers Institute of Technology, Angers, France

Corresponding author:

F Meraghni, Arts et Métiers Institute of Technology, CNRS, Université de Lorraine, LEM3-UMR 7239 CNRS, 4 rue Augustin Fresnel, 57078 Metz, France.

Email: fodil.meraghni@ensam.eu
} 
with the damage mechanisms of a barely visible impact damage (BVID) in woven glass reinforced polyamide $6.6 / 6$ composite.

\section{Keywords}

Thermoplastic woven composite, low-velocity impact damage, damage mechanisms, BVID, permanent indentation, non-destructive evaluation

\section{Introduction}

In the automotive industry, the interest for thermoplastic-based composite materials is continuously evolving during the last few years. This is motivated by their excellent thermomechanical properties (Agrawal et al., 2014), their potential recyclability as well as their reduced production cost. However, the resistance of these composites under impact loading remains among the significant scientific challenges requiring thorough analysis. A comprehensive review paper has been published to discuss the parameters affecting the impact behaviour and the damage initiation and accumulation in composite materials (Agrawal et al., 2014). In terms of mechanical performances, thermoplastic-based composites are known to be highly sensitive towards internal damage caused by low-velocity impact (Sierakowski and Newaz, 1995). It is established that composite structures undergo impacts throughout their life cycle, which can occur i) at the manufacturing stage, ii) during in-service life or iii) during maintenance operations.

The out-of-plane low-velocity impacts generate several damage mechanisms that are not visible nor macroscopically noticeable. This type of damage is commonly noted as Barely Visible Impact Damage (BVID) that represents a detection threshold according to the aerospace industry. Although defects can be difficult to detect on the surface, internal damage may occur and progressively propagates and lead to detrimental consequences. It induces a critical stiffness reduction and can lead to a macroscopic failure of the structural component. To avoid a subsequent loss of the vehicles' integrity, automotive manufacturers tend to use criteria taken from the aircraft industry in order to stand up to the safety requirements with regards to the design requirements of composite structures (Sierakowski and Newaz, 1995). Damage tolerance appears to be an essential aspect to consider when designing composite parts. It is introduced as the capability of a structure to withstand a certain load below an acceptable limit until the damage is detected and hence can be repaired (Hull and Shi, 1993).

When dealing with impact, the composite structures design relies on the detectability of BVID, which is represented as the permanent indentation (PI). The latter is appearing on the external surface of the composite component and is generally related to the depth and the size of the indent that a striker leaves on the sample after impact. Under low energy impact, the permanent indentation phenomena cannot be detected by the naked eye and requires a resolved investigation technique to be reliably measured.

The overall response of fibre-reinforced composite (FRC) subjected to low-velocity impact and the investigation of the related damage mechanisms remain important for identifying the damage tolerance. The behaviour of composite structures under impact loading and the induced degradation have been widely studied (Al-Hajaj et al., 2019; Dhakal et al., 2012; Liang et al., 2015). Basically, the induced impact damage occurs through degradation modes and their accumulation, namely fibre breakage, delamination, transverse matrix cracking and interface debonding. Impact 
response of FRC structures is generally affected by numerous factors such as the impactor geometry, stacking sequence and reinforcement architecture (Shah et al., 2019). The latter along with matrix toughness are considered as primary factors governing impact resistance and energy absorption of composite structures. For that matter, several studies are carried out to assess the influence of the matrix and reinforcement type on damage tolerance (Andrew JJ et al., 2019; Berk et al., 2016; Greenhalgh E and Hiley M, 2003). It is stated that thermoplastic matrices grant important benefits regarding interlaminar delamination and impact resistance.

In addition, several authors studied the effect of woven fabric reinforcement on the behavior of composite materials and the related energy dissipation under compressive dynamic loading (Nachtane et al., 2019; Sassi et al., 2019; Tarfaoui and Nachtane, 2019; Tarfaoui et al., 2019). These studies pointed out that the woven reinforced composites are very competitive compared to unidirectional composites regarding the impact resistance and the induced damage accumulation. Indeed, Greenhalgh and Hiley (2003) showed that woven composites are more resistant to delamination than those with unidirectional reinforcements. Atas and Sayman (2008) analyzed the response of woven composite plates, made of epoxy resin reinforced with glass fibres, to impact loading for increasing energy levels. They established a link between the energy profile and the visually identified damage mechanisms. Kim and Sham (2000) focused on the study of two main aspects: delamination and fracture behavior of a woven composite. Advantages of using this type of composite compared to a unidirectional cross-ply are also highlighted based on the microstructure properties. Generally, the induced internal damage in polymer composites has a penalizing effect on the lifetime of the structures (Kara and Muhammed, 2017) and can be one of the major drawbacks for the use of materials for the automotive structural applications. It is worth mentioning that the environmental conditions influence the behavior, the failure mechanisms and the residual properties of the composite (Cao et al., 2019; Deniz et al., 2013; Weng et al., 2017). Indeed, Deniz et al. (2013) showed that the seawater weakens the interface between the matrix and the fibres and therefore lead to a reduction in the impact resistance. Cao et al. (2019) studied the effect of thermal aging on the damage mechanisms and the residual flexural behavior.

Nevertheless, to attenuate these weaknesses towards structural applications, a proper experimental investigation approach is needed to estimate i) the damage initiation and evolution, ii) the threshold energy relative to significant impact induced damage and iii) the residual properties and performances. In fact, it is of high importance to monitor and to keep under observation parts subjected to low-velocity impact loading to avoid unexpected failures that could occur inservice induced by a progressive BVID. Therefore, the development of experimental techniques that are efficient, rapid, sensitive to damage and not intrusive remains highly required. For this purpose, several Non-Destructive Evaluation (NDE) techniques are extensively developed in the literature. Radiography, thermography, acoustic emission, and ultrasonic-based techniques are the most common among these methods. Thermography analysis is shown to be simple, reliable and fast for detecting low impact damage. Indeed, to evaluate and assess its efficiency, Maier et al. (2014) performed a study comparing the obtained results from thermography with those given by ultrasonic C-scan. Budadin et al. (2019) employed infrared thermography to analyse the dynamic behaviour of a woven fabric and to study the thermal phenomena associated to damage creation. Ravikara et al. (2006) proved that the ultrasonic C-scan could quantify damage induced by this type of loading better than infrared thermography. Furthermore, it is observed that ultrasonic investigation provides specific primordial information for high-quality analysis of impact (Aymerich and Meili, 2000: Castaings et al., 2012). For instance, Margueres et al. (2000) exploited the ultrasonic bulk waves to estimate the stiffness constants for composites subjected to post-impact fatigue loading and the induced damage anisotropy. Techniques using nonlinear elastic waves 
spectroscopy (NEWS) are shown to be promising (Eckel et al., 2017). In this sense, a strong correlation between the damage state and the nonlinear behavior of the transmitted signals is highlighted. Indeed, it was established that this nonlinearity grows with the increase of damage within the samples (Eckel et al., 2017). Polimeno and Meo (2009) employed two different nonlinear approaches to investigate the damage induced by low-velocity drop weight in composite structures intended for aircraft use. They were able to highlight the efficiency of such approaches in providing valuable information relative to damage detection and its severity prediction. Dong et al. (2018) employed terahertz imaging on woven carbon fibre- reinforced composite subjected to four-point bending load. This method is shown to be efficient and sensitive to damage. It is worth noticing that the ultrasonic based techniques usually require for the experimental set-up the use of a coupling fluid. The latter enables the wave propagation and avoids signal attenuation because of impedance mismatch between the air and the material. Nevertheless, the use of the water as a coupling fluid constitutes a drawback and a limit for polymer matrix composites for hydrophilic thermoplastic reinforced composites. As a solution, air-coupled contactless ultrasonic measurement methods are increasingly implemented for material characterization (Imielinska et al., 2004; Fang et al ., 2017). However, these innovative methods are still under development to overcome the impedance mismatch between air and solid materials. Indeed, only a fraction of the acoustic energy can be coupled between air and the samples.

In the same framework of the present paper, Pomarède et al. (2018) presented an experimental procedure, based on different NDE methods, to study damage induced by stepwise increase interrupted quasi-static tensile loading that resulted in two damaged indicators based on phase-shift and the estimation of Frobenius norm. The evolution of these new damage indicators was validated using C-scan imaging and compared with the evolution of the stiffness reduction extracted from mechanical tests. Finally, the correlation with the evolution of the defects content estimated through X-Ray tomography demonstrated the efficiency of the proposed damage indicators.

Based on the previous non-exhaustive bibliographic review, it can be inferred that these NDE techniques are difficult to implement and require a specific knowledge background for the measurement and the post-processing of the data. Complementary quantitative techniques providing accurate estimate of the permanent indentation (PI) are suitable to identify the damage location and to deduce the residual post-impact performance. As a damage indicator, the PI should be related to the occurring damage mechanisms in order to assess the criticality of the impact damage. The latter is generally used to establish an impact damage tolerance criterion for instance (Shah et al., 2019).

This paper aims at developing an innovative experimental procedure to analyze the impact induced damage in a thermoplastic reinforced woven composite towards automotive applications. The developed experimental approach combines several investigation and observation techniques leading hence to the qualitative and quantitative characterization of the BVID in a polyamide 6.6/6 reinforced composite subjected to low-velocity impact. The other objective of the paper is then to assess the reliability of the ultrasonic based estimation of the permanent indentation when employed alone as a damage indicator.

The paper presents the developed experimental approach applied for evaluating the damage induced by a low-energy impact and its related effects. Besides the stiffness reduction, the paper focuses also on a different main damage indicator consisting in the permanent indentation measurements that represents a key parameter for the post-impact damage analysis. To this end, several NDT methods are carried out and their experimental findings are cross-linked to analyze the permanent indentation and the induced damage mechanisms. First, visual post-impact investigation is performed on the non-impacted surface of the samples along with data analysis of the impact test showing that the size of damage increases with the impact energy. Afterwards, ultrasonic C-scan 
and B-scan imaging are introduced to estimate the permanent indentation (PI). These measurements are then validated using the resolved 3D optical profilometry. The identification of the different damage mechanisms using X-ray micro computed tomography is achieved and yields to a proposition of a damage chronology. The permanent indentation representing the damage on the impacted surface is then correlated with respect to the impact energy. Finally, the variation of the stiffness constants is estimated using experimental ultrasonic data to solve Christoffel's equation.

\section{Material and microstructure's description}

The material of the study is a woven twill 2.2 composite referred to as VizilonTM SB63G1-T1.5-S3, manufactured by DuPont de Nemours using a thermo-compression molding process. It is a copolyamide $6.6 / 6$ (thermoplastic matrix) reinforced with a layup of three balanced glass fibre layers oriented at $0^{\circ} / 90^{\circ}$. The composite, with a thickness of $1.53 \mathrm{~mm}$, has a fibre weight ratio of $63 \%$ corresponding to a fibre volume fraction of $43 \%$.

The Table 1 provided by DuPont de Nemours presents the density, the Young modulus (E) and the ultimate strength $\left(\sigma_{\mathrm{UTS}}\right)$ and strain $\left(\varepsilon_{\mathrm{UTS}}\right)$ of the studied composite material. The microstructure and the architecture of the material reinforcement are presented in Figure 1.

Polyamides are semi-crystalline polymers known to be sensitive towards temperature variation and relative humidity (Arif et al., 2014; Benaarbia et al., 2014, 2015). The hydrogen bonds, between the amide molecules, tend to be weakened by water absorption. Consequently, the mobility in the polyamide chains increases leading to what is called 'plasticizing' effect of water. This kind of polymers can be characterized by two important temperatures; melting point $\mathrm{T}_{\mathrm{m}}$ and glass transition temperature $T_{g}$. An increase of the temperature leads to an increase of ductility and a decrease of Young modulus, along with a drop of $\mathrm{T}_{\mathrm{g}}$. The latter is also affected by the variation of the relative humidity due to the water uptake. It drops with the increase of the moister content (Benaarbia et al., 2014).

Moreover, the moisture content might influence the damage mechanisms created in a polyamide based composite. Indeed, the damage mechanisms are varying in the material from one relative humidity to another. Arif (2014) has shown that different predominant damage mechanisms are observed between samples conditioned at $0 \% \mathrm{RH}$, and $50-100 \%$ conditioned samples. For $0 \% \mathrm{RH}$,

Table I. Mechanical characteristics of the studied woven glass fabric-PA66-6 composite.

\begin{tabular}{llllll}
\hline $\begin{array}{l}\text { Mechanical } \\
\text { characteristics }\end{array}$ & Density & $\begin{array}{l}\text { E_0 } 0^{\circ}(\mathrm{GPa}) \\
\text { warp direction }\end{array}$ & $\begin{array}{l}\text { E_90 }(\mathrm{GPa}) \text { weft } \\
\text { direction }\end{array}$ & $\begin{array}{l}\sigma_{\mathrm{UTS}}(\mathrm{MPa}) \\
\text { warp direction }\end{array}$ & $\begin{array}{l}\varepsilon_{\mathrm{UTS}}(\%) \\
\text { warp direction }\end{array}$ \\
\hline & 1.78 & 17.7 & 18.1 & 303 & 1.9 \\
\hline
\end{tabular}
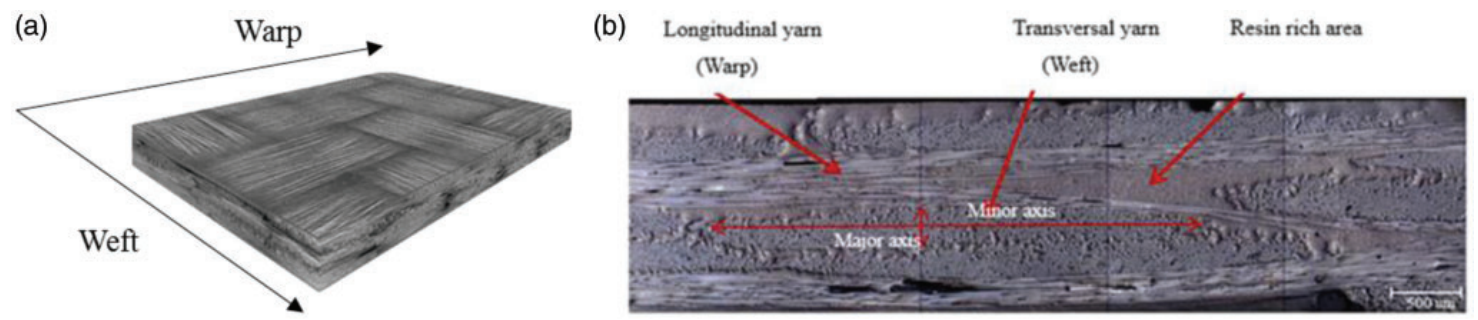

Figure I. Mesostructure (a) and microstructure microscopic observation (b) of the woven glass fabric-PA66-6 composite showing warp and weft orientation (Pomarède et al., 20l8). 
fibre/matrix debonding at fibre ends and sides, fibre breakages and brittle matrix crack propagation are identified. Meanwhile, fibre/matrix debonding at fibre ends and sides with a locally strained matrix zone around the debonded fibres along with ductile matrix micro-cracks are observed in the sample with a $50 \%$ RH. At a $100 \% \mathrm{RH}$, the same damage mechanisms as those observed at 50\% RH are retrieved, but with a higher severity, in addition to matrix deformation local shear bands.

Pomarède (2018) studied the tensile response of the PA6.6/6 reinforced composite under two configurations $0^{\circ}$ and $45^{\circ}$. It is shown that the mechanical behaviour is highly influenced by the fibres' orientation. Indeed, under tension loading, the $0^{\circ}$ configuration behaves as a linear and brittle while at $45^{\circ}$ configuration shows a nonlinear ductile response due to the matrix rheology. Typical stress-strain curves showing the response of the woven glass reinforced PA6.6/6 at $0^{\circ}$ (or $90^{\circ}$ ) and that at $45^{\circ}$ directions are given in Figure 2. The components of stiffness matrix are determined experimentally using ultrasonic bulk waves (Pomarède, 2018) and are compared with those obtained numerically using periodic homogenization (Praud, 2018) as represented in Table 2.

In the present work, impact test are carried out on samples manually cut using a water-cooled circular saw. The plates have rectangular shape of 100 by $150 \mathrm{~mm}$ dimensions and $1.53 \mathrm{~mm}$ thickness, in agreement with the ASTM D7136/D7136M standards. Afterwards, the initial undamaged states is verified for all samples using ultrasonic C-scan, and are maintained next at the same initial conditions in terms of temperature (room temperature) and relative humidity (dry as molded).

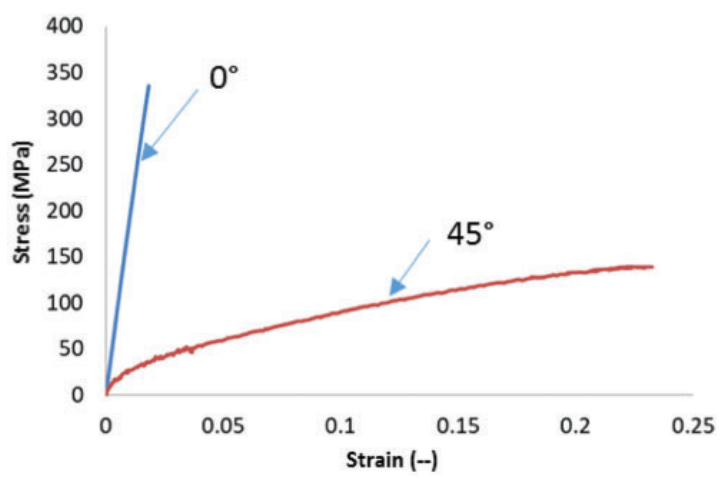

Figure 2. Typical stress-strain responses of the woven glass fabric-PA66-6 composite under tensile loading in $0^{\circ}$ and $45^{\circ}$ directions (Pomarède, 2018).

Table 2 . Numerical and experimental stiffness tensor of the studied material (Pomarède, 2018).

\begin{tabular}{|c|c|c|c|c|c|c|c|c|c|}
\hline $\begin{array}{l}\text { Stiffness tensor } \\
\text { components (GPa) }\end{array}$ & $C_{11}$ & $C_{12}$ & $C_{13}$ & $\mathrm{C}_{22}$ & $\mathrm{C}_{23}$ & $\mathrm{C}_{33}$ & $\mathrm{C}_{44}$ & $\mathrm{C}_{55}$ & $C_{66}$ \\
\hline $\begin{array}{l}\text { Numerical estimation } \\
\text { (using periodic } \\
\text { homogenization) }\end{array}$ & 20 & 2.1 & 1.5 & 20 & 1.5 & 4.5 & 2.3 & 1.3 & 1.3 \\
\hline Experimental & $\begin{array}{l}22.21 \\
(0.2)\end{array}$ & $\begin{array}{l}2.57 \\
\quad(0.15)\end{array}$ & $\begin{array}{l}\text { I. } 4 \text { I } \\
\quad(0.76)\end{array}$ & $\begin{array}{l}21.81 \\
\quad(0.08)\end{array}$ & - & $\begin{array}{l}4.1 \\
\qquad(0.07)\end{array}$ & $\begin{array}{l}2.33 \\
\quad(0.09)\end{array}$ & $\mathrm{I} .58(0.2 \mathrm{I})$ & - \\
\hline
\end{tabular}




\section{Experimental procedures}

\section{Drop weight impact tests}

Impact tests are performed using a drop tower equipped with a $1.02 \mathrm{Kg}$ striker having a $16 \mathrm{~mm}$ diameter hemispherical end. The experimental device, shown in Figure 3, consists of a piezoelectric load sensor and two laser displacement sensors, as well as a data acquisition system. The plates are clamped at both ends as illustrated in Figure 3, and the impactor strikes the plates in their centre. The displacement of the sample is subsequently measured under the impacted plate using a laser displacement sensor. The acquisition of the striker's (impactor) displacement, the displacement of the centre of plate, and the contact force are measured for data analysis. The main objective of this project is to study the BVID and its detectability in rectangular cross-sections samples made of thermoplastic polymer (PA6.6/6) reinforced glass woven fabric composite. For that matter, four impact energy levels are considered by varying the drop height in such a way to remain in the BVID domain. The four impact energy levels resulting from the variation of the drop height are: $7.30 \mathrm{~J}$, $13.45 \mathrm{~J}, 15.28 \mathrm{~J}$, and $17.60 \mathrm{~J}$.

In the following subsections, the damage investigation techniques employed to detect and quantify the degradation induced by the impact tests are presented.

\section{X-ray tomography investigation}

To inspect deeply the effect of the impact loading on the studied composite, the X-Ray micro-computed tomography investigation is carried out. The X-Ray images acquisition is achieved using EasyTom (Nano) device developed by RX solutions. This imaging method determines the impact zones,

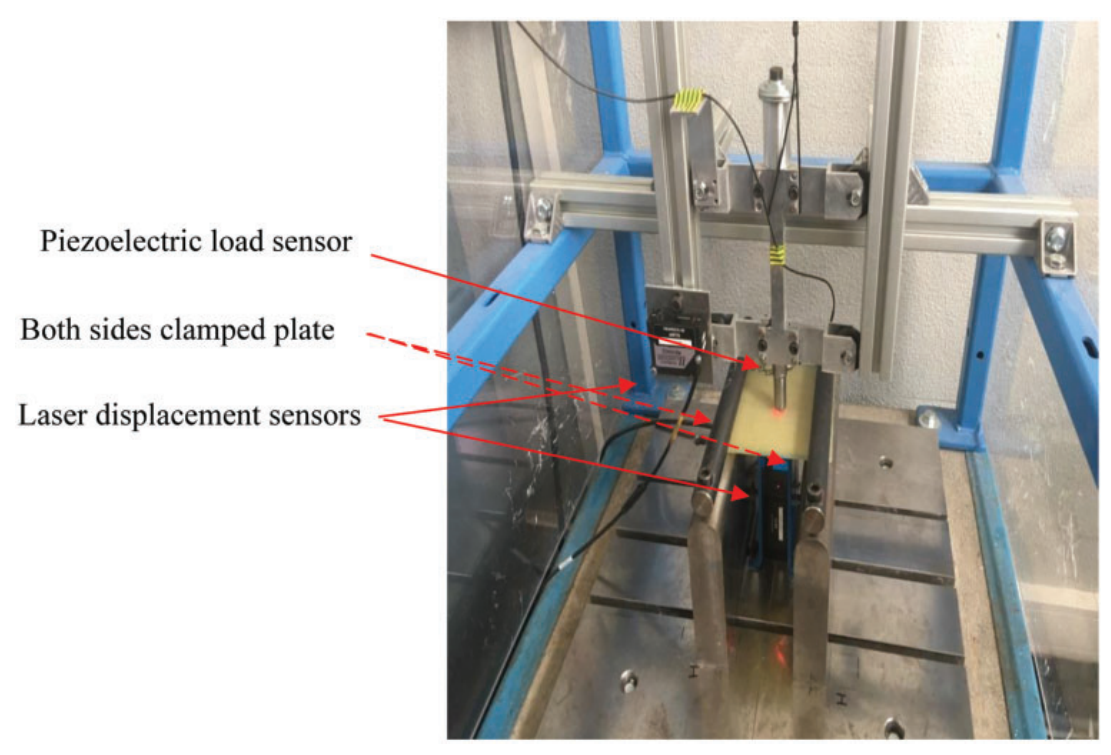

Figure 3. The experimental device used to perform drop weight impact tests showing: a piezoelectric load sensor, a first laser displacement sensor that monitors the displacement of the striker and a second one placed under the clamped sample to record the deflection. 


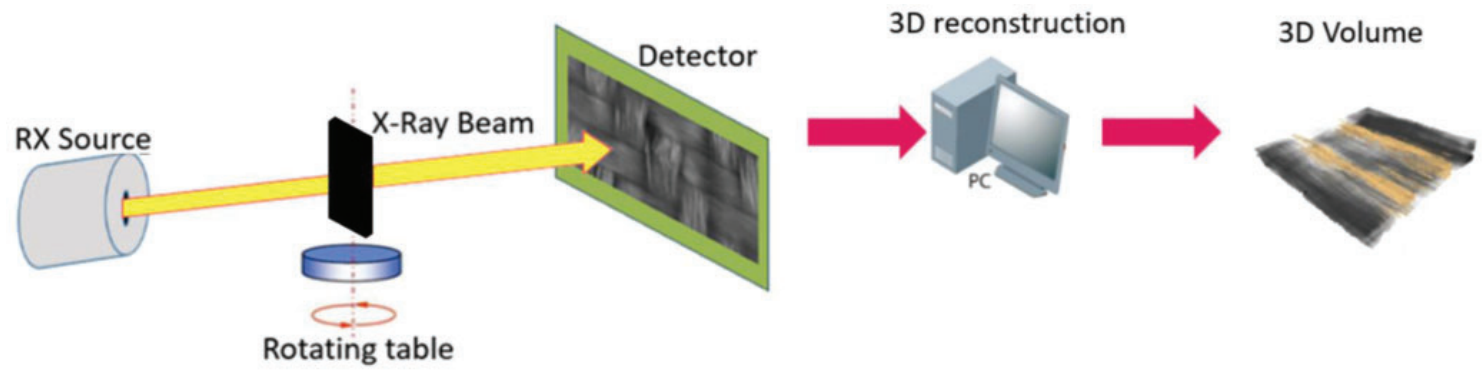

Figure 4. Principle of X-Ray tomography technique: the investigated object is first positioned on a rotating table; the $X$-Rays penetrate it and are then projected on a flat detector.

distinguishes the different damage mechanisms and traces the propagation path of the induced damage with a suitable spatial resolution. Following the principle of the X-Ray tomography detailed in

Figure 4, the X-Ray beam penetrates the sample, which is positioned on a rotating table and is then projected on a flat panel detector. Its ability to provide internal information about the investigated area makes the technique more suitable and helpful compared to other in-situ investigation methods. A voxel size is set to $12 \mu \mathrm{m}$ corresponding to the resolution of the observation. It represents a good compromise in terms of accuracy up to the level of the fibre diameter ranging from 10 to $15 \mu \mathrm{m}$. Radiographic images recorded at different rotation angles and thicknesses are then processed for the $3 \mathrm{D}$ volume reconstruction of the targeted area of the sample. The data post-processing and the 3D reconstruction of the area of interest are achieved using X-Act software. AVIZO software is employed afterward to significantly reduce the amount of noise in the reconstructed images employing the median filter and the related thresholding levels that the software provides.

\section{Ultrasonic C-scan imaging}

The ultrasonic C-scan method is carried out to detect and to characterize the damage in terms of localization and evolution in the composite plates. The acquisitions are performed using a customerdesign five axes immersion scanner made by Inspection Technology Europe BV. The pulses are generated using the dual pulse-receiver DPR500 made by JSR ultrasonics. The experimental data acquisition is achieved via Winspect software and post-processed using a Matlab code. Two types of $\mathrm{C}$-scan modes are utilized: transmission and reflection mode (Pulse/echo). For the C-scan in transmission, two $10 \mathrm{MHz}$ transducers are positioned above and below the plate, as illustrated in Figure 5. The scanned area is of $130 \mathrm{~mm} \times 90 \mathrm{~mm}$, and the spatial resolution is $0.3 \mathrm{~mm}$. The displacement speed is $20 \mathrm{~mm} / \mathrm{s}$ along the $\mathrm{X}$ Axis and $10 \mathrm{~mm} / \mathrm{s}$ along the $\mathrm{Y}$ Axis. The top transducer is the transmitter, and the bottom transducer is the receiver. The transducers are set up in a manner that assures that the plate is located at the same distance from the two. With the help of a robot, on which the transducers are positioned, C-scans following a serpentine path are performed. This setup allows the measurement of the wave's maximum amplitude for each point of the scanned sample. An attenuation of the signal is observed when a defect is encountered.

Reflection C-scan is performed to obtain further information concerning in-thickness damage propagation. A single focused $10 \mathrm{MHz}$ piezoelectric transducer is used for this purpose. The latter emits an ultrasonic wave that is reflected when encountering defects or inhomogeneities and is later recorded and analysed. The samples are positioned in such a way that the impacted surface is facing the transducer (Figure 6). C-scan images corresponding to the scanned area are later presented. 


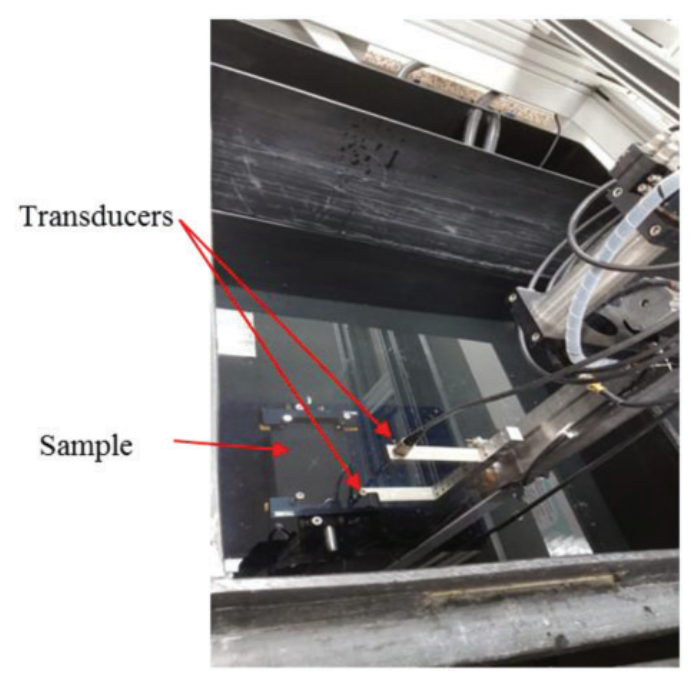

Figure 5. Transmission C-scan setup showing a clamped sample immerged in a tank filled with water and two $10 \mathrm{MHz}$ transducers that scan the sample following a serpentine path.

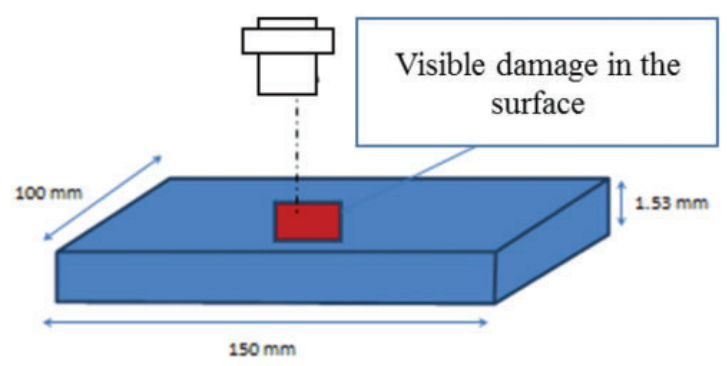

Figure 6. Pulse/echo $\mathrm{C}$-scan configuration using one single $10 \mathrm{MHz}$ transducer that plays the role of both the emitter and the receiver.

It should be noted that in both cases, the entire measuring system (transducers and plates) is immersed in a water-filled tank (Figure 5). Unlike air, the water as a coupling fluid has the advantage for providing better ultrasound coupling.

\section{Permanent indentation (PI) measurement}

After localizing the damaged area on each sample using C-scan in reflection, ultrasonic B-scan observations are performed in order to extract information relative to the permanent indentation (PI). It should be indicated that in this case $\mathrm{C}$-scans are carried out with the impacted surface facing the transducer and with a spatial resolution of $0.2 \mathrm{~mm}$. The same ultrasonic apparatus, as well as the $10 \mathrm{MHz}$ transducers, are adopted for this investigation.

An optical profilometry method is performed to confirm the accuracy of this measurement. A LEICA DCM3D (Figure 7) is employed with $\times 5$ magnification, imaging an area of $27 \times 20.23 \mathrm{~mm}$. Each sample is scanned according to predefined steps during which each point of 


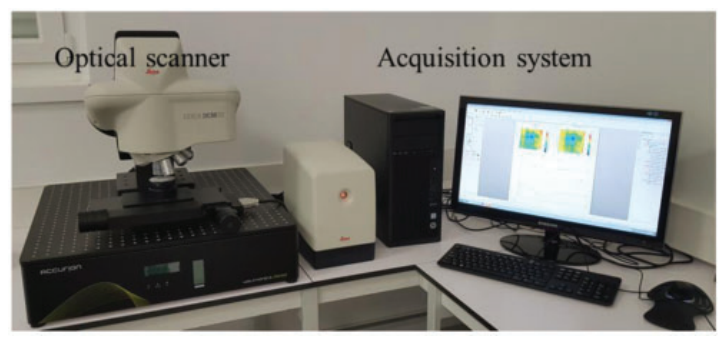

Figure 7. Leica DCM3D device showing the optical scanner and the acquisition system.

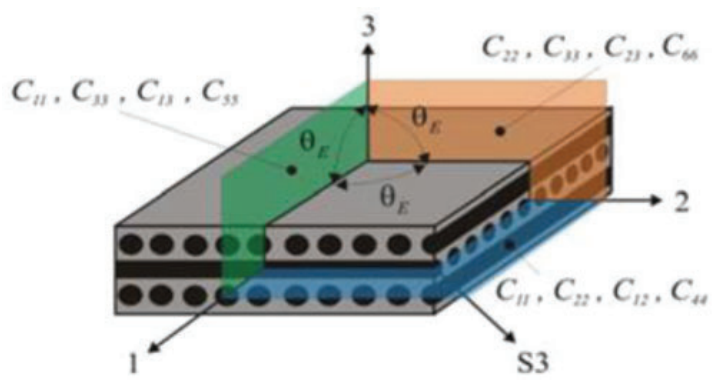

Figure 8. Schematic representation of the considered planes to perform the experimental stiffness measurements in composites (Hufenbach et al., 2006).

the surface crosses the focal plane. The magnification leads to a resolution along $\mathrm{X}$ and $\mathrm{Y}$ of $0.94 \mu \mathrm{m}$, and the vertical resolution less than $150 \mathrm{~nm}$.

\section{Experimental stiffness components measurements}

In order to quantify the influence of the impact damage on the mechanical properties of the studied material, an experimental stiffness components measurements method, that was described and used by our research team (Pomarède et al., 2018), is employed. The main idea of this method is to determine the velocity of the propagating wave at different incidence/emission angles on the different principal planes (Figure 8). The velocity of wave propagation along with the stiffness and density of a solid homogeneous medium are linked by the equation known as Christoffel's equation:

$$
\left(C_{i j k l} n_{k} n_{j}-\rho v^{2} \delta_{i j}\right) U_{l}=0
$$

$\left(C_{i j k l}\right)$ the stiffness tensor, $n$ the vector normal to the wave plane, $\rho$ the density of the sample, $v$ the phase velocity, $\delta$ the Kronecker delta symbol and $U$ the polarization vector of the mechanical wave.

For each angle in each considered plane, the experimental velocity of the wave propagating in the sample is retrieved by estimating the time delay $\delta_{\mathrm{t}}$ using the principle illustrated on Figure 9. The time delay represents the difference between the time of flight (TOF) of the ultrasonic wave in the water i.e without the sample and the TOF of the wave with the sample. 


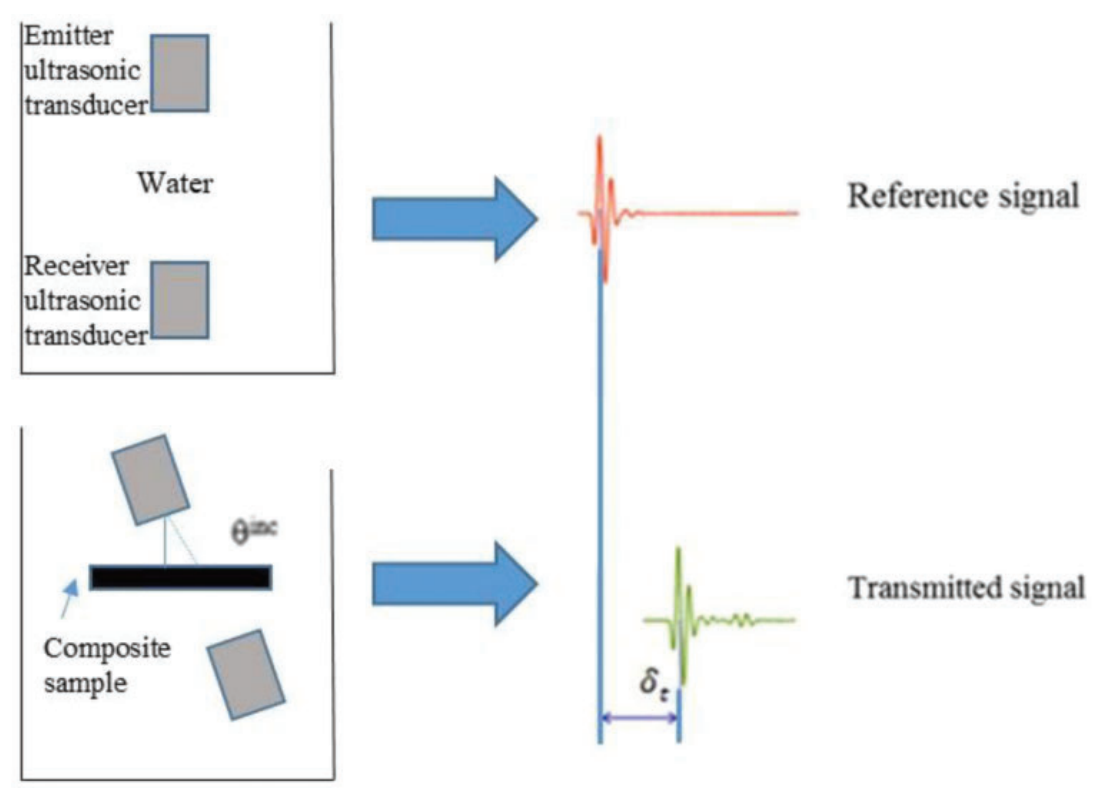

Figure 9. Illustration of the measurement of the time delay [Inspired from perso.univ-lemans.fr].

Then, a Levenberg-Marquardt minimization algorithm uses the experimental velocities and compares them to numerical values obtained by solving the Christoffel equation for a given set of $\mathrm{C}_{\mathrm{ij}}$. It is highly important to initiate the algorithm with a first guess of $\mathrm{C}_{\mathrm{ij}}$ close to the real solution. For further details, the reader can refer to Margueres and Meraghni (2013), Pomarede P, et al. (2018), Dalmaz A (2000). In this case, the initialization values are computed by periodic homogenization and are presented in Table 2 (Praud et al., 2017).

Since the use of Christoffel's equation relay on the assumption that the material is considered as an homogeneous medium (Dalmaz, 2000), the wavelength of the wave traveling through the material needs to be bigger than the smallest microstructural features of the undamaged sample. Therefore, the wavelength have to be higher than the fibers dimension. Consequently, a transducer with a central frequency of $2.25 \mathrm{MHz}$ is employed to satisfy the hypothesis of the homogeneous media. The signals acquisitions are performed using the same experimental equipment detailed in the Ultrasonic C-scan imaging section. Due to the samples dimensions, the measurements of bulk waves in transmission are carried out in the planes 1-3 and 2-3 but not in the plane 1-2. Indeed, the measurements, in transmission, in the plane 1-2 can cause the wave passing by the sample and not through it because of the small thickness of the sample.

In the next section, experimental results of all the performed investigation methods are presented and discussed in terms of damage detection and accumulation.

\section{Experimental results and discussion}

A thorough analysis of the collected data during the impact tests is performed to understand the response of a woven composite subjected to low-velocity impact. Afterward, a quantification of the induced damage using NDE techniques is carried out. More precisely, this section will be organized as follows: i) an analysis of the impact test results for all energy levels, ii) an X-Ray tomography 


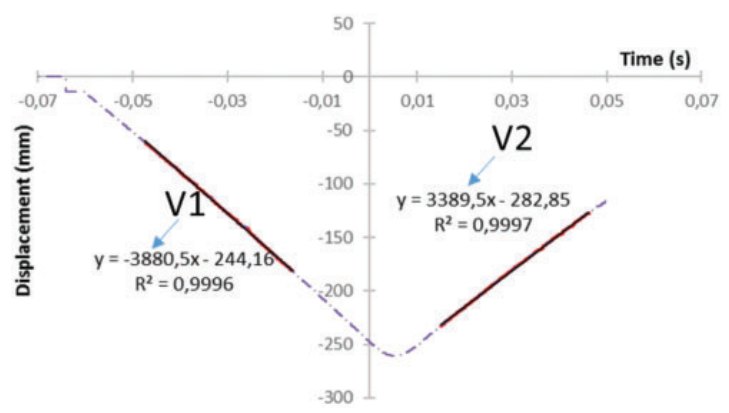

Figure 10. Impactor's displacement- time curve for the sample loaded at $7.30 \mathrm{~J}$ detailing the followed method to compute the absorbed energy.

investigation and identification of different damage mechanisms, iii) ultrasonic C-scan imaging and iv) a quantification of permanent indentation as an induced impact damage indicator.

\section{Impact response analysis and macroscopic damage observations}

As mentioned previously in the Drop weight impact tests section, the drop weight impact tests are performed considering four different energies: $7.30 \mathrm{~J}, 13.45 \mathrm{~J}, 15.28 \mathrm{~J}$, and $17.60 \mathrm{~J}$.

It is worth mentioning that the interest of the impact loading is the initiation of a damage under a moderate loading rate in relation with a given progressive low impact energy levels, namely the BVID.

These tests provided data for the analysis of the studied material response. The recorded data using the striker displacement sensor is employed to compute the impact velocity as well as the absorbed energy $\left(E_{A}\right)$. The latter corresponds to the amount of energy passing from the striker to the sample during an impact event. In this study, this energy is given as the difference between the impact energy (obtained using the impact velocity) and "the excessive energy" (computed using the rebound velocity) as referred to Dhakal et al. (2012). The absorbed energy is expressed as the difference between both energies using the following equation:

$$
E_{A}=\frac{1}{2} m\left(v_{1}^{2}-v_{2}^{2}\right)
$$

$v_{1}$ and $v_{2}$ are respectively the impact and the rebound velocities. They are determined as the slopes of respectively the first part and the second part (rebound) of the displacement-time curve, as illustrated in Figure 10.

$(m)$ is the striker's (impactor) mass $(\mathrm{m}=1.02 \mathrm{Kg})$

All estimated velocities correspond to the slope of the best straight line fitted through the real values, where the regression's coefficient is close to 1 . Figure 10 presents an example of the sample impacted at $7.30 \mathrm{~J}$ where the velocities are estimated using the displacement-time curve of the impactor. The calculated impact parameters are listed in Table 3. As expected, one can notice that the absorbed energy increases with impact energy show in Figure 11(c). Indeed, damage severity and formation can be directly linked to the increase of the absorbed energy. Figure 11 presents deflection-time (a) and contact force-time (b) curves, respectively, for the four impact energy levels. On all curves (force and displacement), a noticeable shift of the amplitude between the response at $7.30 \mathrm{~J}$ and the response at the rest of the impact energy levels could be easily observed. Figure 11(a) 
Table 3. Instrumented drop weight impact parameters: drop height, impact velocity, real impact energy and absorbed energy.

\begin{tabular}{llll}
\hline Impact height $(\mathrm{m})$ & Impact velocity $(\mathrm{m} / \mathrm{s})$ & Real impact energy $(\mathrm{J})$ & Absorbed energy $(\mathrm{J})$ \\
\hline $\mathrm{I}$ & 3.88 & 7.30 & 1.78 \\
1.5 & 5.18 & 13.45 & 5.66 \\
1.75 & 5.53 & 15.28 & 7.01 \\
2 & 5.93 & 17.60 & 8.93 \\
\hline
\end{tabular}

(a)

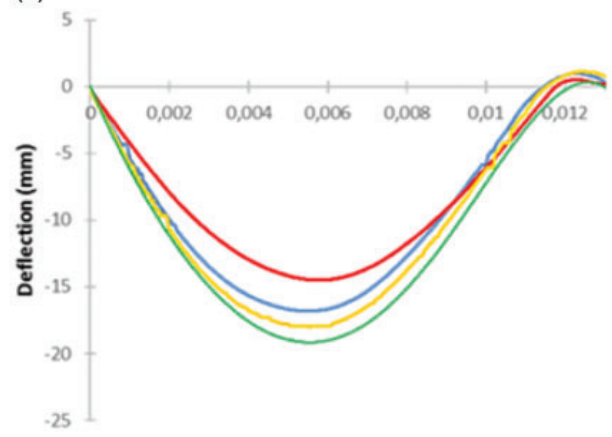

(c)

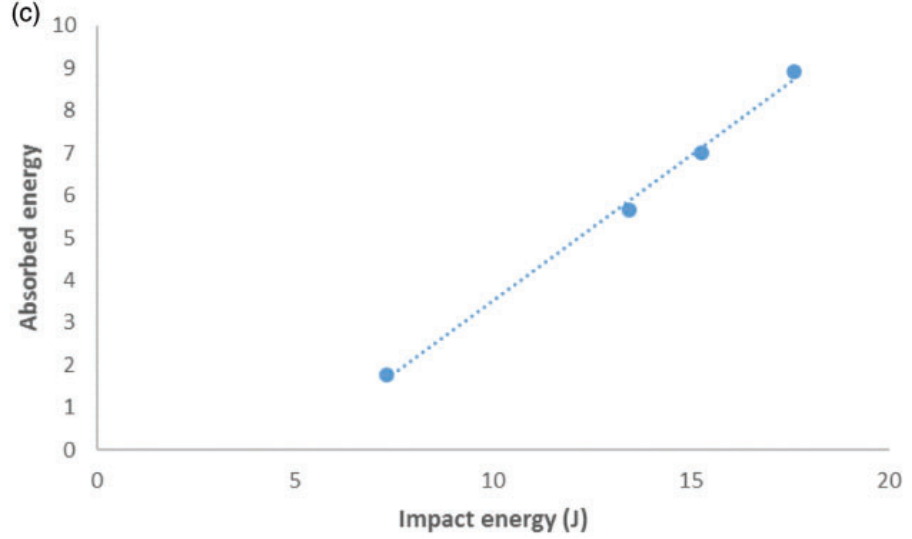

(b)

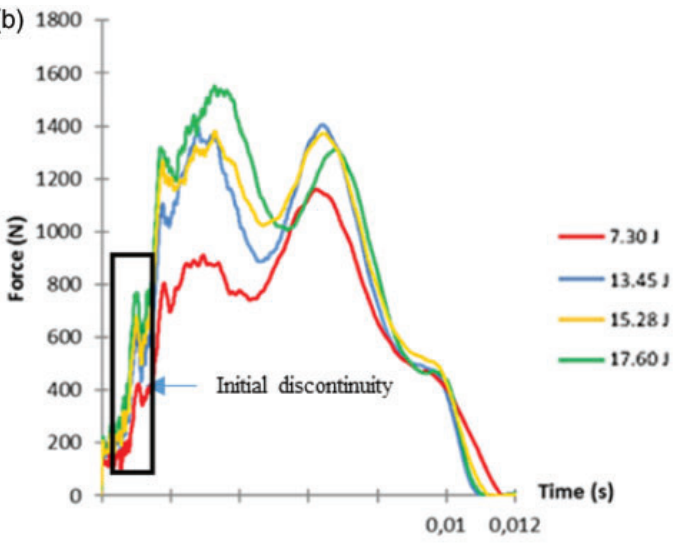

Figure II. (a) Displacement -time curves and (b) force-time curves for the four considered drop weight energies, (c) the absorbed energy-impact energy.

illustrates the aforementioned displacement-time curves. One should mention that for the curve referring to the sample loaded at $17.60 \mathrm{~J}$, a regression is achieved due to difficulties inherent to the acquisition (saturation of the sensor at certain areas). As expected, the maximum deflection of the impacted specimen grows with the impact height. On Figure 11(b), the maximum contact force increases along with the growth of the impact energy. In all force-time histories, oscillations and discontinuities of high and low frequencies are observed. The first type of oscillations can be attributed to the natural frequencies of the impactor and are known as "impactor ringing." The severity of the oscillations increases if the parts constituting the impactor are not rigidly attached 


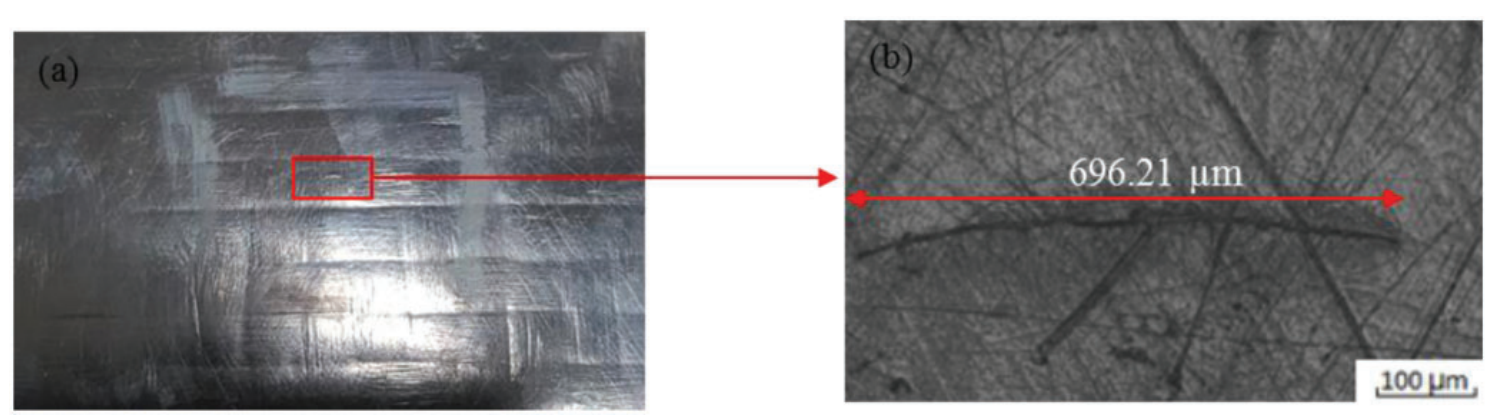

Figure 12. Images of the micro crack seen on the back of the plate damaged at 13.45 J: (a) naked eye observation (b) image obtained using an optical microscope.

(Gliszczynski et al., 2018). The second type of oscillations is the flexural response (vibration) of the impacted sample. One should note that both types of oscillations occur during initial contact and could probably be linked to damage induction (Abrat, 1998). Nevertheless, the first discontinuity (a decrease followed by an increase) marked with a black rectangle on Figure 11(b) should be discriminated from the rest of the oscillations. It could be considered as initial discontinuity due to the first contact between the impactor and the plate.

After the impact tests, no visible damage is observed on the specimen loaded at an energy level of 7.30 J. However, on the three other specimens, damage appearing on the non-impacted surface could be observed by the naked eye. It should be mentioned that all damage observed during this study occur on the non-impacted side of the specimens. Indeed, based on the literature (Abrat, 1998) for the case of thin plates, the damage is initiated on the bottom layer and propagate in a pine tree path caused by the bending stress and waves propagation.

The first observed damage stage is on the specimen impacted at an energy level of $13.45 \mathrm{~J}$. This damage appeared as a small opening on the non-impacted side, barely visible to the naked eye. To investigate the small damage closely on the plate impacted at $13.45 \mathrm{~J}$, an observation using the optical microscope is performed. Figure 12 exhibits the obtained images of the superficial damage with a dimension of $696.21 \mu \mathrm{m}$. However, on the samples impacted at $15.28 \mathrm{~J}$ and $17.60 \mathrm{~J}$, cracks propagating longitudinally and transversely leading to fibre breakage are easily observed (Figure 13).

\section{X-ray tomography investigation}

Several damage phenomena are observed on the 3D reconstruction. The severity of the damage grows at increased impact energy. On the plate impacted at $7.30 \mathrm{~J}$, no damage is observed. Indeed, impact energy of the magnitude of $7.30 \mathrm{~J}$ appears to be not sufficient for bring about a permanent internal damage in the material. Figures 14 to 16 represent the images resulting from X-Ray tomography inspection for each impacted sample. On the plate impacted at $13.45 \mathrm{~J}$, shown in Figure 14, a small crack is noticed to be superficial. For the other two plates $(15.28 \mathrm{~J}$ and $17.60 \mathrm{~J})$, damage reaching fibres-breakage is observed (Figures 15 and 16).

The primary damage mechanism detected for the plates impacted at $15.28 \mathrm{~J}$ and $17.60 \mathrm{~J}$ during $\mathrm{X}$-Ray tomography investigation is matrix cracking. The cracks detected on the non-impacted side are propagated, in thickness, in the composite following the fibre orientation. These cracks diffuse into and along the yarns in a transversal and longitudinal path. After crossing the first ply and assuming that the propagation energy is high enough, the cracks could evolve and turn into 

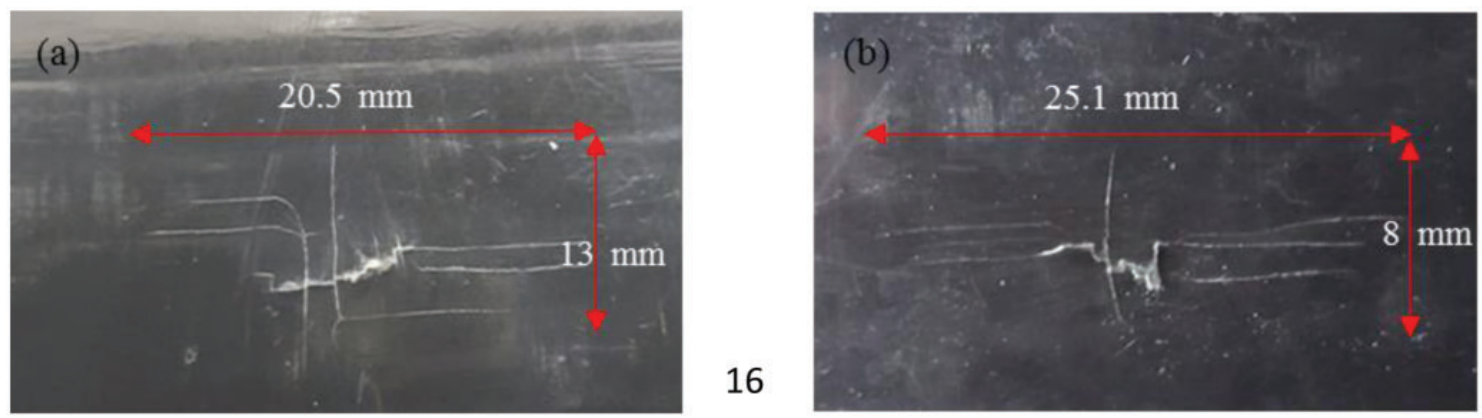

Figure 13. Dimensions of the damage occurring on the impacted samples loaded at energy of (a) $15.28 \mathrm{~J}$ and (b) $17.60 \mathrm{~J}$ observed by naked eye.

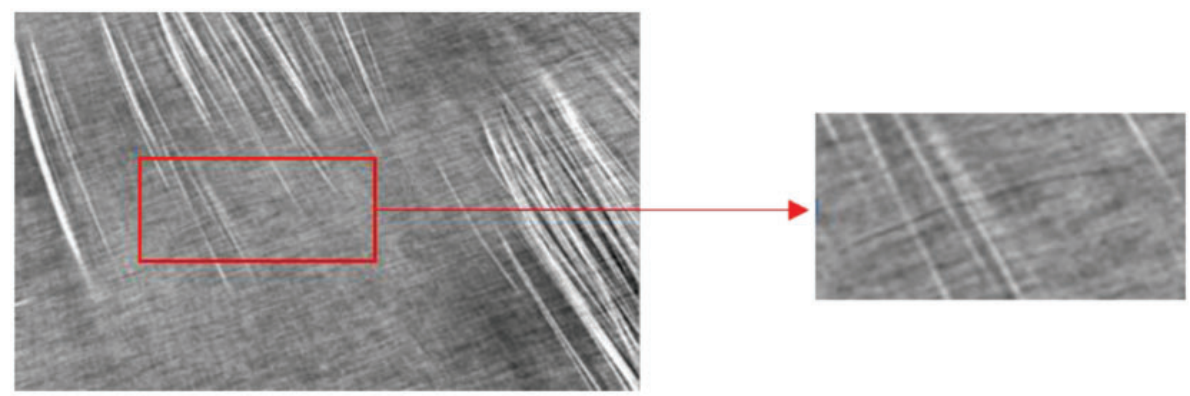

Figure 14. X-ray tomography observations performed on the samples impacted at an energy level of 13.45 J showing the matrix micro-crack.

delamination that spread around the yarns. This damage mechanism is called pseudo-delamination. It is highly relevant to note that in a laminate composite made of plies having the same fibre orientation, no delamination could occur on the interface between the layers (Abrat, 1998). As shown in Figure 15, some cracks penetrate the yarns of the second ply but do not extend to the third layer. It should be highlighted that matrix cracks, and the resulting delamination engender defects inside the samples. The latter, when exposed to X-Rays, appear as black areas that constitute the crack network.

On the sample side containing visible damage, fibre breakage can be observed. When observing the fibre breakage area in the perpendicular plane, a slight lift of the broken zone is noticed. This uplift induces delamination that appears between transversal and longitudinal yarns inside the same ply.

As a partial conclusion, one can establish that the damage mechanisms developed in a woven glass reinforced composite undergoing impact loading are similar to those appearing after a monotonous loading. The damage chronology for the initiation and accumulation is as follows: on the impacted surface, the matrix cracks propagate in both longitudinal and transversal direction with a more pronounced propagation along the longitudinal direction due to the boundary conditions of the impacted plate. The cracks propagate into the yarns leading to the deterioration of the interface between the fibres and the matrix. The cracks then spread between the yarns corresponding to a rich matrix zone, inducing the failure of the reinforcement layer. The present damage scenario is definitely in agreement with the literature (De Baere et al., 2012; Osada et al., 2003). 

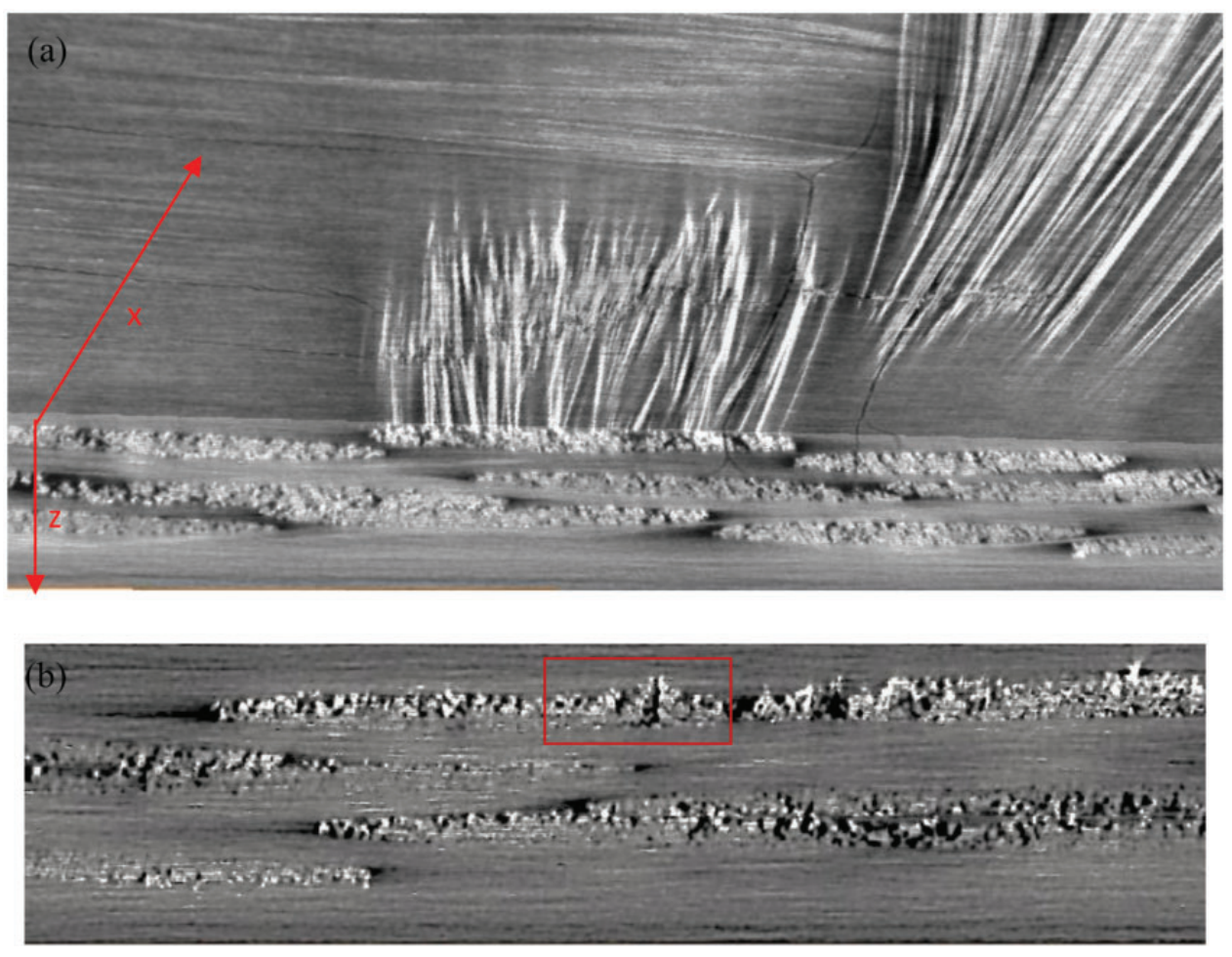

Figure I5. X-ray tomography observations performed on the samples impacted at an energy level of I5.28 J showing (a) the crack network and (b) a transversal crack and delamination.

\section{Ultrasonic C-scan results}

As specified in the Ultrasonic C-scan imaging section, two types of ultrasonic C-scan tests are carried out on the loaded samples, namely transmission and reflection tests. Results of ultrasonic C-scan are represented as cartographies of amplitude (Figures 17 and 18). The isocolor map reflected the variation of the maximal amplitude on the various areas of the scanned surface. The blue color corresponds to an attenuated signal and therefore small amplitude. These blue areas indicate the zones with high probability to contain damage, while the red areas reveal the zones where the signal amplitude reached its maximum value.

Figure 17 demonstrates the results of C-scans in transmission. Relatively small areas at the edges and inside the plates showed an attenuation that indicates a low amount of damage. It can be presumed that the latter was introduced during the cutting process or manufacturing. Thus, it is considered irrelevant and is neglected in the sequel.

For the sample submitted to a $7.30 \mathrm{~J}$ impact, no potential damage is noticed on the scan image. At $13.45 \mathrm{~J}, 15.28 \mathrm{~J}$ and $17.60 \mathrm{~J}$ impact energies, all $\mathrm{C}$-scan in transmission images exhibited signal attenuation that is localized near the impact region. No difference in term of damage dimension is observed. That said, it is highly challenging to differentiate between the three plates.

Figure 18 shows the results of reflection C-scans. The color scale is adjusted to focus more on the areas of amplitude attenuation. Pulse/echo C-scan results (Figure 18(c) and (d)), for 15.28 J and $17.60 \mathrm{~J}$ as energy level) presented damage surface evolution when the impact energy increased. On 

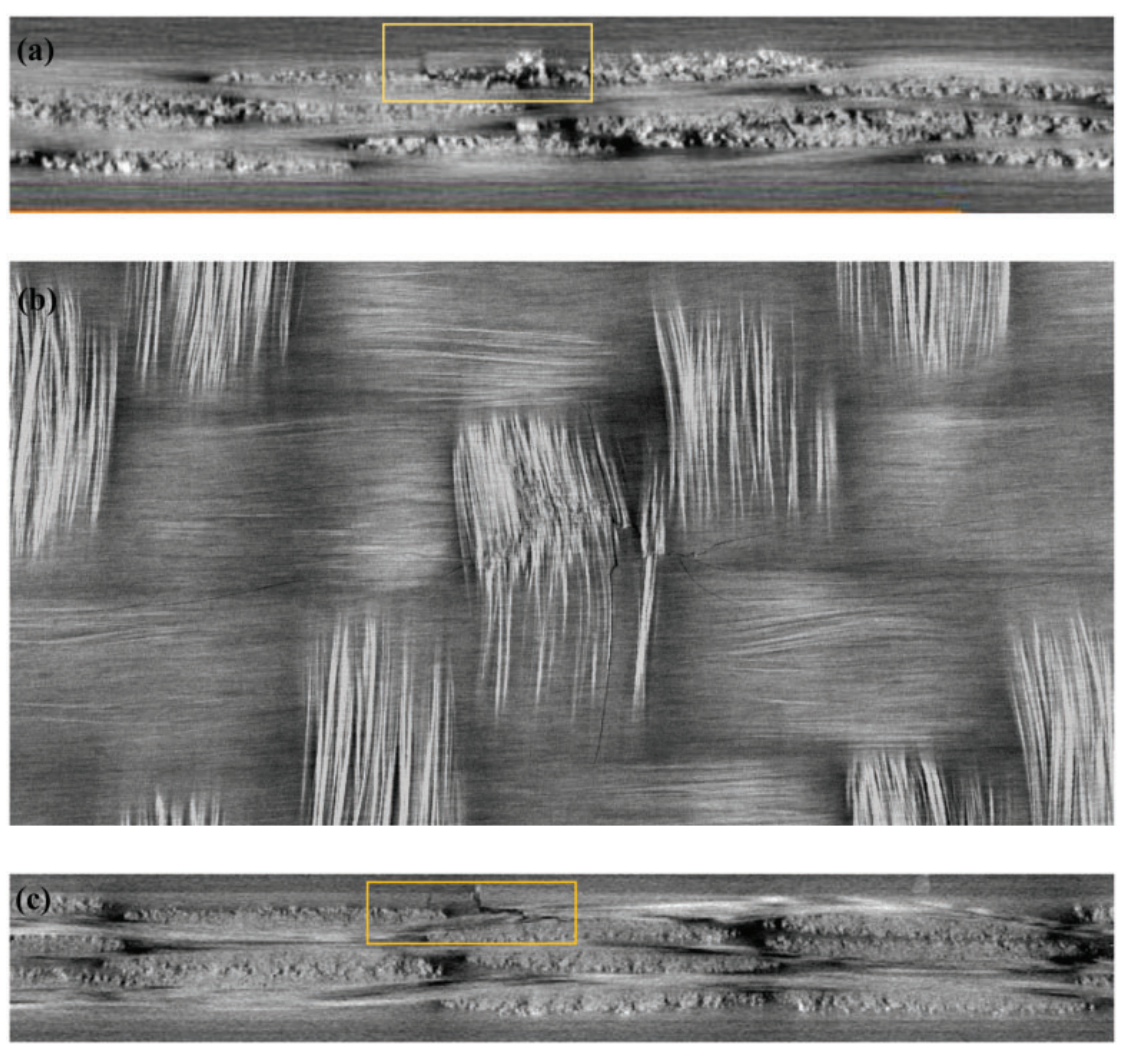

Figure 16. X-ray tomography observations performed on the samples impacted at an energy level of 17.60 J showing (a) a local uprising of the fibres localized between two transversal crack, (b) the crack network and (c) delamination and stair-shape failure.

the other hand, no defect is detected for the two samples damaged at 7.30 J and 13.45 J. In Table 4, the detected defect dimensions are shown. For an energy level of $15.28 \mathrm{~J}$, the damaged area observed on the C-scan image corresponds to a dimension of $5 \mathrm{~mm}$, while for the plate corresponding to an energy level of $17.60 \mathrm{~J}$, the dimension is $7 \mathrm{~mm}$. These given measures might only represent the area with severe damage due to the limited spatial resolution of such imaging method $(300 \mu \mathrm{m})$.

In conclusion, ultrasonic C-scan imaging provides sufficient information concerning the detection of macroscopic damage. However, it is not accurate for measuring the defect dimensions. Moreover, pulse/echo C-scan cannot be considered as a highly reliable method regarding microscopic damage detection, especially when the damage does not exhibit an in-thickness propagation.

\section{Permanent indentation estimation}

Ultrasonic measurement. An estimation of the dimension of the indent (Figure 19), using ultrasonic inspection, is performed in this sub-section. To do so, the time of arrival corresponding to the first positive peak on the C-scan in reflection is extracted and is illustrated on an isocolor map. In order to explain the procedure, only one example relative to the sample damaged at an energy level of $17.60 \mathrm{~J}$ is presented in Figure 20. Information about the depth of the indent is calculated by measuring the difference between the time of arrival corresponding to the impacted area and the one 

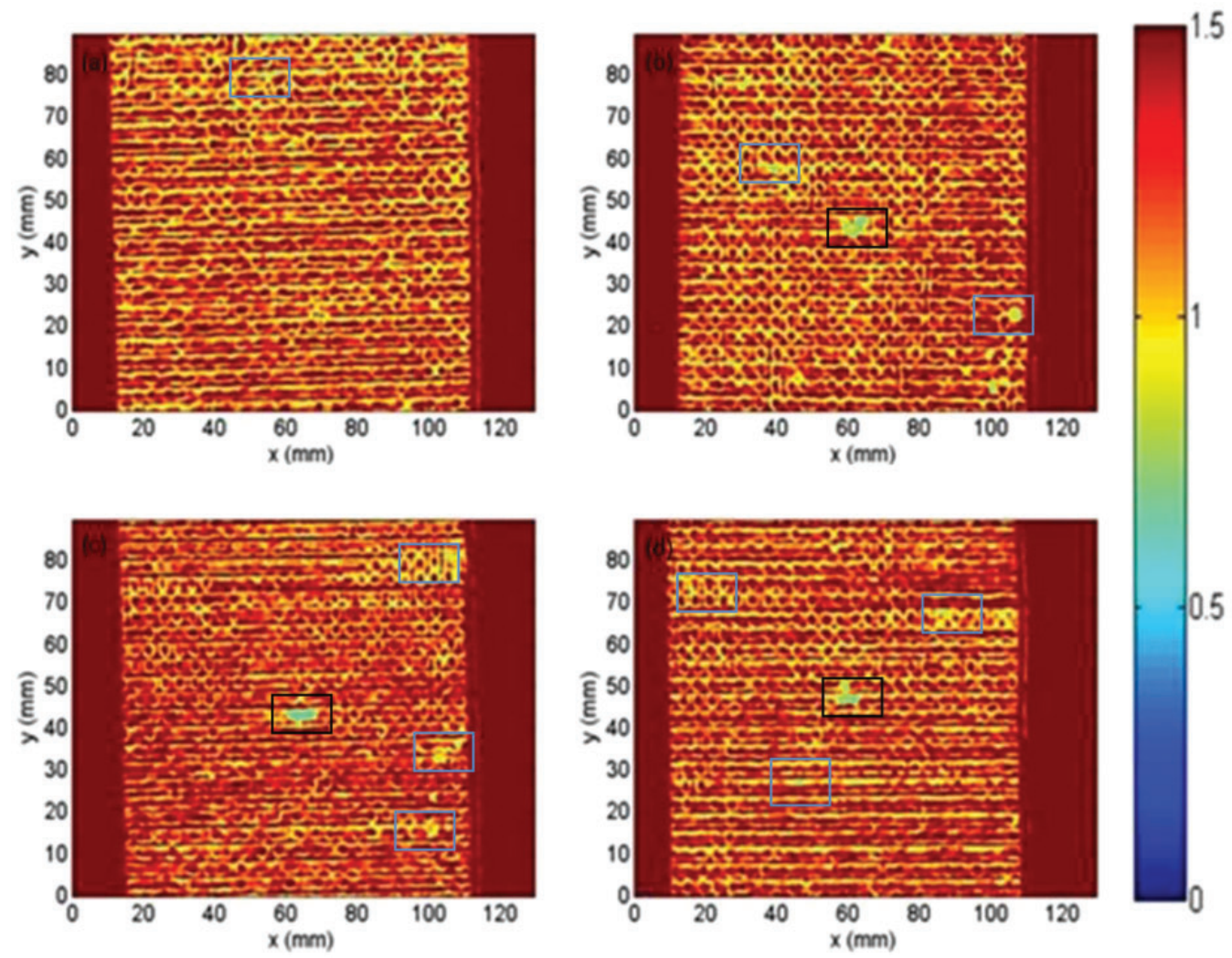

Figure 17. Transmission C-scan results for the four samples damaged respectively at: $7.30 \mathrm{~J} \mathrm{(a),} \mathrm{I3.45} \mathrm{J} \mathrm{(b),} \mathrm{I5.28} \mathrm{J} \mathrm{(c)}$ and $17.60 \mathrm{~J}(\mathrm{~d})$ using the $10 \mathrm{MHz}$ transducers.

corresponding to the non-impacted area. Knowing that the wave propagation velocity is of $1478.8 \mathrm{~m} / \mathrm{s}$ in water, an estimation of the travelled distance for the four plates is given in Table 5 . These distances correspond to the depth of the indent (Figure 20(b)). A substantial increase of PI dimensions, depth, and diameters, is noticed when elevating the impact energy between $13.45 \mathrm{~J}$ and $15.28 \mathrm{~J}$. However, a slight difference from $15.28 \mathrm{~J}$ to $17.60 \mathrm{~J}$ is noted. Nevertheless, ultrasonic measurement of the PI comes with significant uncertainty as mentioned in Table 5.

Optical imaging profilometry: Validation of experimental measurement. A second technique is performed to assess the previous results obtained by the ultrasonic method. It consists of optical profilometry. The scans are carried out following the procedure previously detailed in the Permanent indentation (PI) measurement section. The raw data are then obtained and several post-processing procedures are performed using Leica Maps software as depicted in Figure 21(a). First, a filter, Figure 21(b) is used to elevate the surface around the impacted area and to separate the roughness from the waviness. The primary purpose is to identify the location of the indentation area and then the PI is accurately measured. In fact, the profile is extracted in the line corresponding to the deepest area. This latter provides information about the depth of the permanent indentation Figure 21(c). Finally, by selecting the area of interest point by point, the software calculates the volume of the permanent 

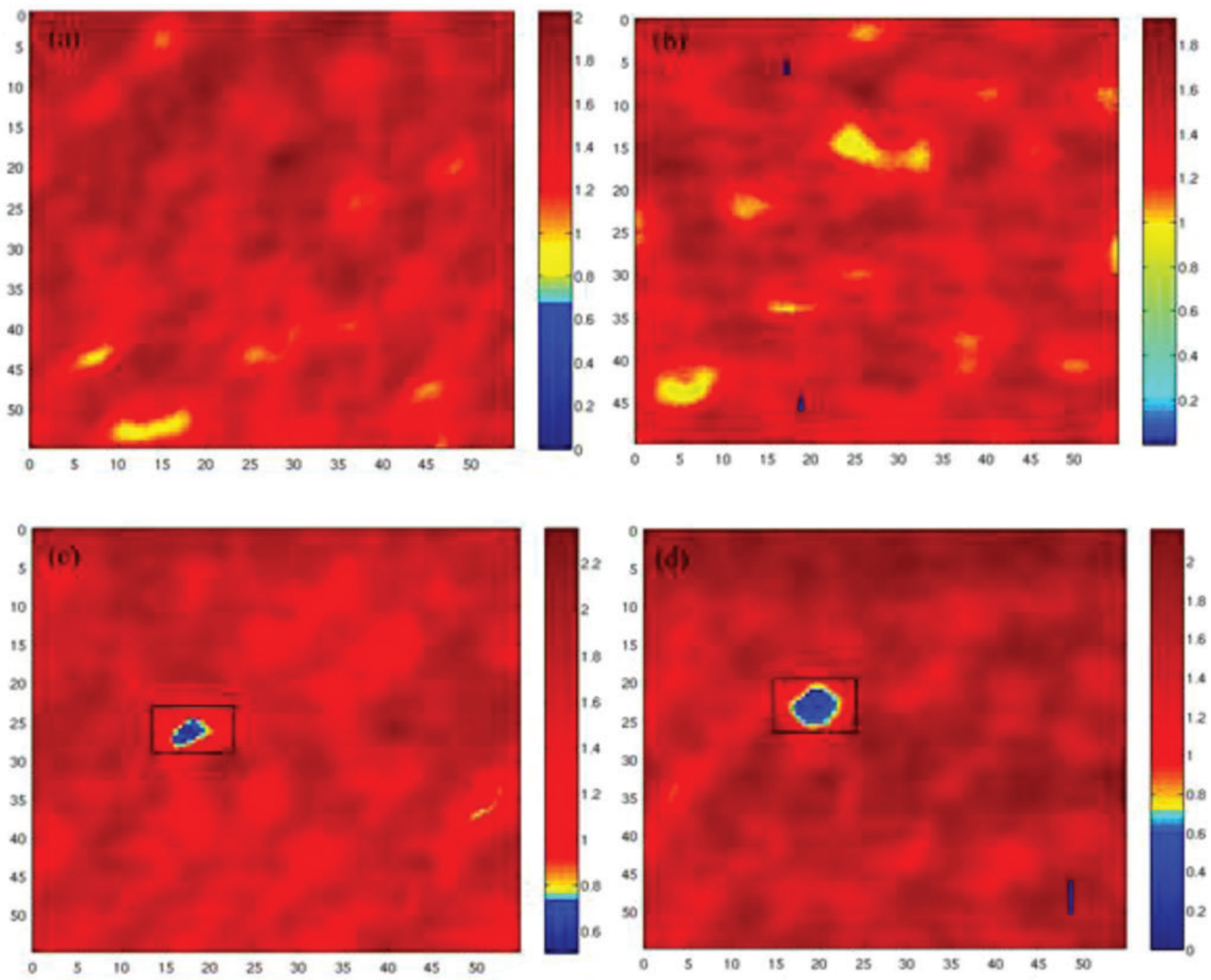

Figure 18. Pulse/echo C-scan results for the four impacted samples: (a) 7.30 J, (b) 13.45 J, (c) I5.28 J and (d) 17.60 J using a $10 \mathrm{MHz}$ transducer.

Table 4. Damage size evolution, measured from pulse/echo C-scan results, with the increase of impact energy.

\begin{tabular}{lllll}
\hline Impact energy $(\mathrm{J})$ & 7.30 & 13.45 & 15.28 & 17.60 \\
\hline Damage dimension $(\mathrm{mm})$ & Not observed & Not observed & 5 & 7 \\
\hline
\end{tabular}

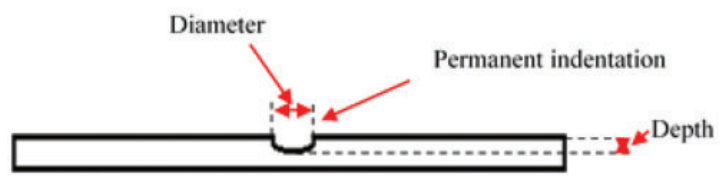

Figure 19. Illustration of the permanent indentation (PI) on an impacted sample. 

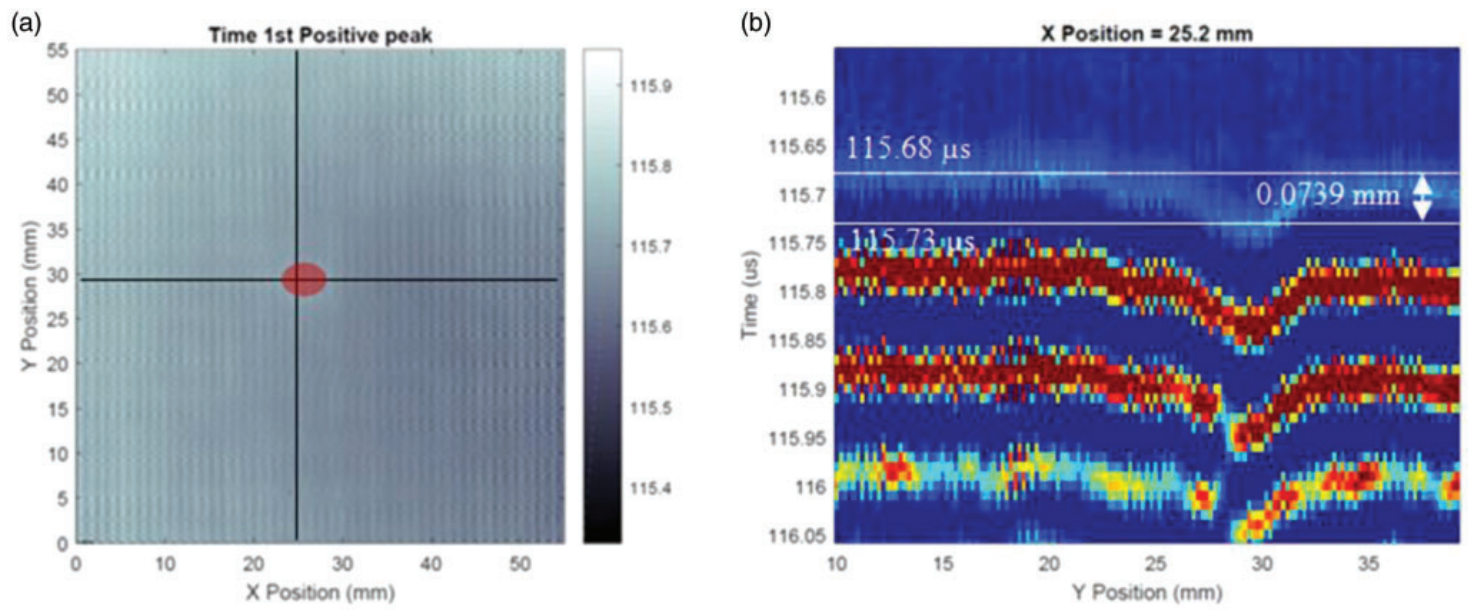

Figure 20. (a) Representation of the cartography corresponding to the time of arrival of the first positive peak, (b) B-scan on the impacted at an energy level of $17.60 \mathrm{~J}$.

Table 5. Values of the PI parameters (diameters and depth) for the four samples impacted respectively at $7.30 \mathrm{~J}$, $13.45 \mathrm{~J}, 15.28 \mathrm{~J}$ and $17.60 \mathrm{~J}$.

\begin{tabular}{lllll}
\hline Impact energy & $7.30 \mathrm{~J}$ & $13.45 \mathrm{~J}$ & $15.28 \mathrm{~J}$ & $17.60 \mathrm{~J}$ \\
\hline Diameters $(\mathrm{mm}) \pm 0.2 \mathrm{~mm}$ & - & 3 & 6.4 & 6.8 \\
Depth $(\mu \mathrm{m}) \pm 7 \mu \mathrm{m}$ & - & 23 & 44 & 37 \\
\hline
\end{tabular}

indentation Figure 21(d). Information relative to the depth, the diameter and the volume of the scanned area is presented in Table 6.

A comparison between the results provided by the two methods, ultrasound-based method, and optical profilometry, is established and represented in Figure 22. The comparison shows a good correlation between the two methods as well as a satisfying accuracy for the ultrasoundbased method.

\section{Experimental stiffness components measurements}

As explained in the Experimental stiffness components measurements section devoted to ultrasonic velocities measurement, the acquisition frequency is set to $2.25 \mathrm{MHz}$ enabling hence to consider the composite material as an homogeneous orthotropic media (Dalmaz, 2000).

Due to the low thickness of the samples $(1.53 \mathrm{~mm})$, the ultrasonic measurements are achieved in two principle planes, namely: $1-3$ and $2-3$ as shown in Figure 8 . These measurements lead to the computation of seven out of nine of the stiffness constants.

Figure 23(a) to (d) represent the experimentally determined stiffness components for the four studied samples. An overall decrease of the stiffness components is noticed starting from $15.28 \mathrm{~J}$. The results are in agreement with those obtained using other techniques. Indeed, one can notice that all the components, namely: $\mathrm{C}_{11}, \mathrm{C}_{22}, \mathrm{C}_{33}, \mathrm{C}_{13}, \mathrm{C}_{55}, \mathrm{C}_{23}$ and $\mathrm{C}_{66}$ exhibit a distinguished decrease starting from the energy of $15.28 \mathrm{~J}$. Furthermore, the stiffness reduction of the components $\mathrm{C}_{11}$ and $\mathrm{C}_{13}$ is more pronounced between $15.28 \mathrm{~J}$ and $17.60 \mathrm{~J}$ rather than between $7.30 \mathrm{~J}$ and $13.45 \mathrm{~J}$. 
(a)

Raw data

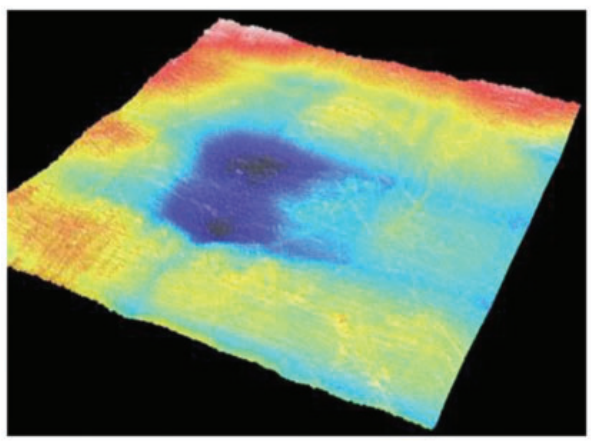

Profil extraction

(c)

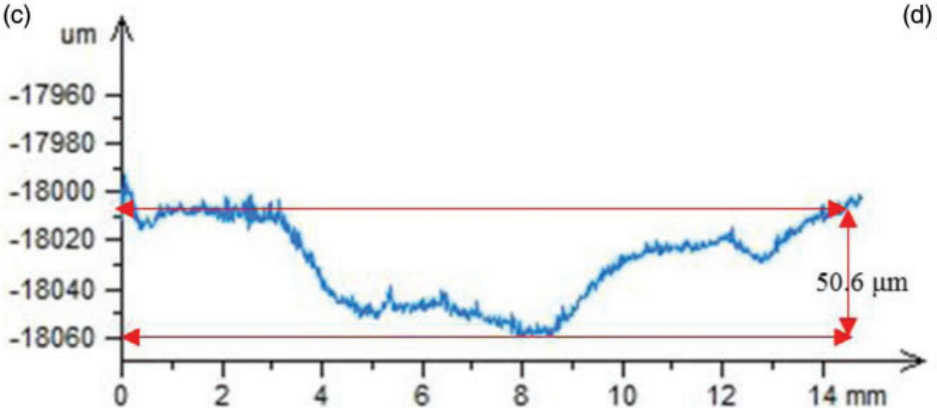

(b)

Filtred data

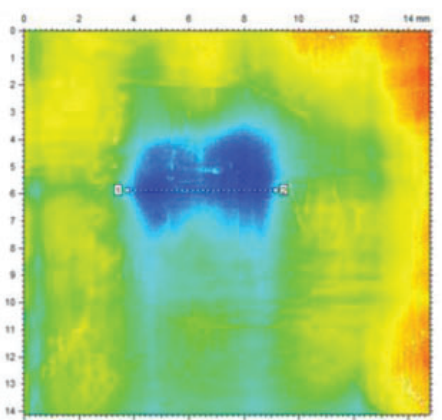

Volume extraction

(d)

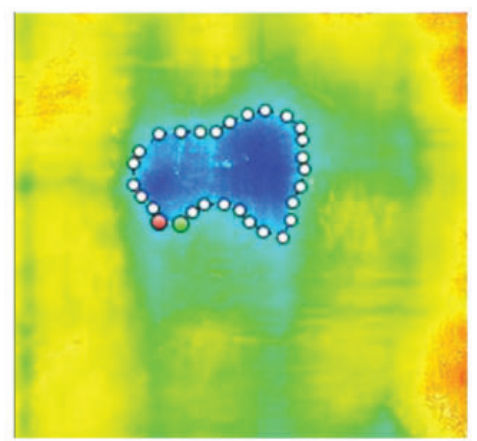

Figure 21. Detailed processing procedure using Leica Maps performed on the plate impacted at 15.28 J: (a) raw data, (b) filtered data, (c) profile extraction and (d) volume extractions.

Table 6. Depth, diameter and volume of the indent using Leica DCM3D Dual core profile device with objective magnification of $x 5$.

\begin{tabular}{lllll}
\hline Impact energy $(\mathrm{J})$ & 7.30 & 13.45 & 15.28 & 17.60 \\
\hline Diameter $(\mathrm{mm}) \pm 0.94 \mu \mathrm{m}$ & 2.09 & 1.92 & 5.10 & 5.77 \\
Depth $(\mu \mathrm{m}) \pm 0.130 \mu \mathrm{m}$ & 25.8 & 27.6 & 50.6 & 54.1 \\
Volume of the indent $\left(\times 10^{-3} \mathrm{~mm}^{3}\right)$ & 35.6 & 37.2 & 138 & 107 \\
\hline
\end{tabular}

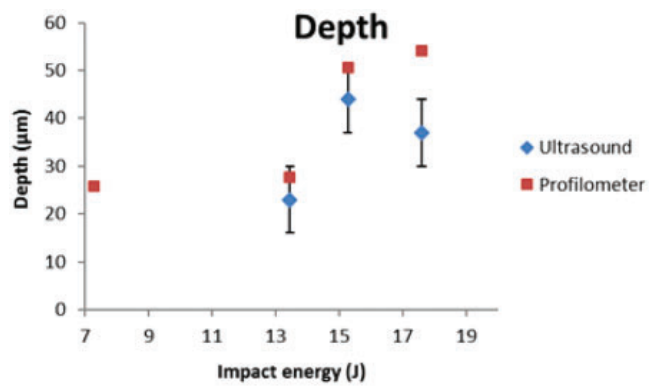

Figure 22. Comparison between the results obtained using both ultrasound-based method and profilometry for the four samples impacted respectively at energies of: 7.30, 13.45, 15.28 and 17.60 J. 
Overall analysis and cross-linked discussion of the experimental results

The utilized NDE techniques and the related analysis discussed below lead to the following outcomes:

- For the sample impacted at an energy of $7.30 \mathrm{~J}$, no damage is detected using X-Ray tomography and $\mathrm{C}$-scan imaging. Consequently, when measuring the permanent indentation using B-scan, no
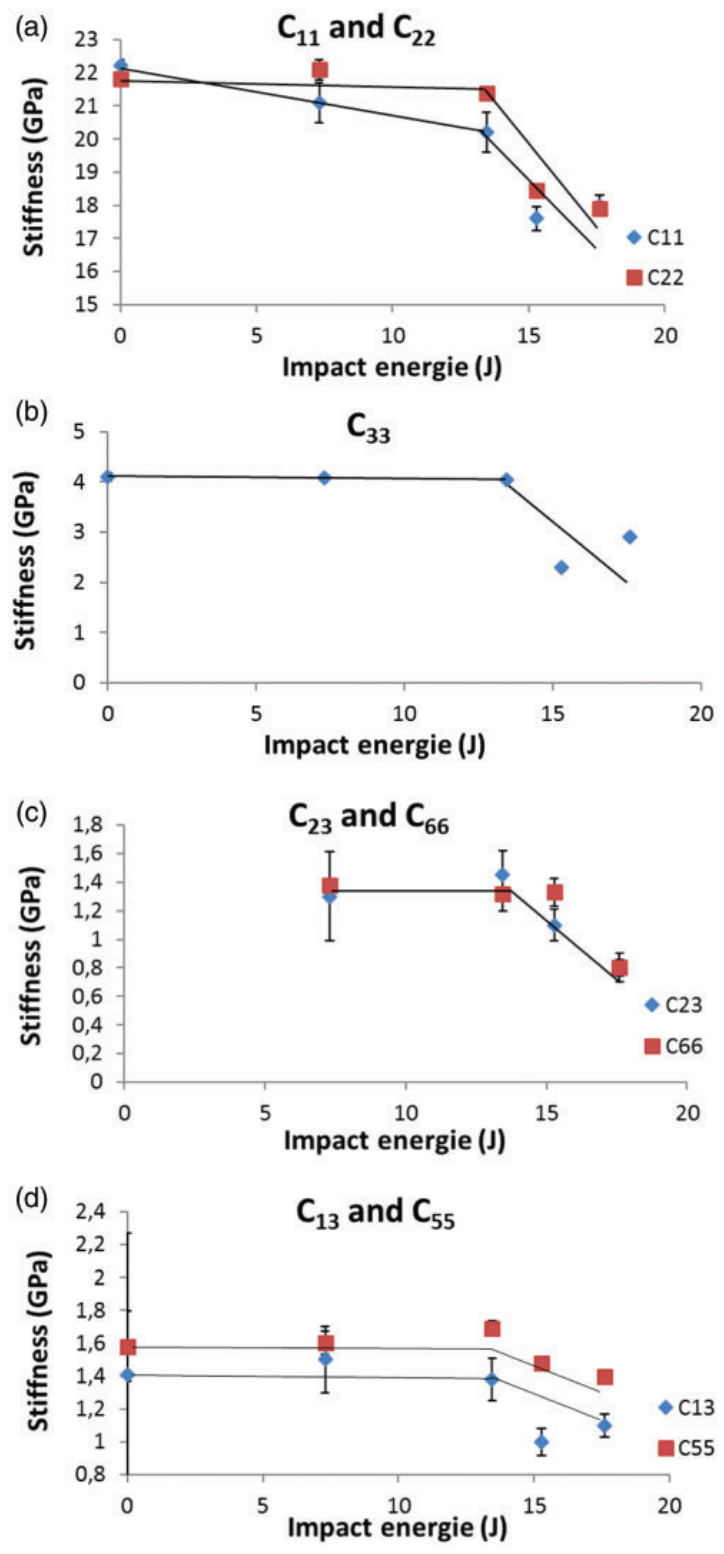

Figure 23. Experimental stiffness components for the samples impacted at energies of $7.30 \mathrm{~J}, 13.45 \mathrm{~J}, 15.28 \mathrm{~J}$ and 17.60 J showing: (a) $C_{11}$ and $C_{22}$, (b) $C_{33}$, (c) $C_{23}$ and $C_{66}$ and (d) $C_{13}$ and $C_{55}$. 
Table 7. Theoretical impact energy, the computed absorbed energy and the corresponding depth and damage mechanisms.

\begin{tabular}{|c|c|c|c|}
\hline Impact energy (J) & Absorbed energy (J) & PI depth (mm) & Damage mechanisms \\
\hline $7.30 \mathrm{~J}$ & $\mathrm{I} .78$ & - & - \\
\hline $13.45 \mathrm{~J}$ & 5.66 & 0.023 & Matrix micro-cracking \\
\hline $15.28 \mathrm{~J}$ & 7.01 & 0.044 & $\begin{array}{l}\text { Matrix micro-cracking } \\
\text { Delamination Fibres breakage }\end{array}$ \\
\hline $17.60 \mathrm{~J}$ & 8.93 & 0.037 & $\begin{array}{l}\text { Matrix micro-cracking } \\
\text { Delamination Fibres breakage }\end{array}$ \\
\hline
\end{tabular}

change in the impacted surface is captured. Moreover, no reduction, if any, of the stiffness components is noticed.

- For the three other impact energies, $13.45 \mathrm{~J}, 15.28 \mathrm{~J}$ and $17.60 \mathrm{~J}$, an essential increase of the absorbed energy is computed indicating damage creation. This hypothesis is verified by visual inspection that showed a small opening on the non-impacted side for the sample loaded at $13.45 \mathrm{~J}$ and $\mu \mathrm{CT}$ that confirms that the seen damage does not extend to the first layer and is indeed superficial.

More pronounced damage is detected for the samples impacted at $15.28 \mathrm{~J}$ and $17.60 \mathrm{~J}$. Thus, damage extending to the second layer of the composite is observed. The cracks propagated through the matrix breaking the yarns (longitudinal and transversal) leading to the creation of delamination. On the impacted side, the measure of the permanent indentation using B-scan imaging show a critical increase starting from $15.28 \mathrm{~J}$. The verification of these measures by optical profilometry lead to an agreement between the two used methods. An overall decrease of the stiffness components is noticed starting from $15.28 \mathrm{~J}$.

By identifying the residual damage on both surfaces, impacted and non-impacted, and in thickness, one can establish a link between the absorbed energy, the dimensions of the permanent indentation, the internal damage, i.e. damage mechanisms and the stiffness reduction. Indeed, by measuring the PI, one can predict the resulting damage mechanisms and determine to what extent the damage propagates in the thickness direction as well as the effect of damage creation on the rigidity evolution. "Thus, one can rely only on the PI measurement, using and/or profilometry, as a damage indicator to determine the criticality of the damage on the composite sample."

Table 7 illustrates the impact energy, the corresponding PI depth, and the identified damage mechanisms.

\section{Concluding remarks}

The current study presents both a qualitative and a quantitative characterization of damage induced by low-velocity drop weight impact on a polyamide based woven composite using different NDE techniques. The purpose of this study was to provide a reliable characterization of the induced damage using the developed experimental methodology and to link all the obtained results to the Permanent Indentation (PI) measurement. This link establishes the reliability of the ultrasonic based proposed methodology when applied alone for the damage investigation in composite materials.

$\mathrm{X}$-Ray micro computed tomography allowed the identification of the resulting damage mechanisms and led to the suggestion of a damage scenario. Matrix cracking appeared first in the nonimpacted surface and propagate along yarns in a transversal and a longitudinal path. When the energy 
was high enough, it has grown into delamination that spread between the damaged yarn and the perpendicular yarn just underneath. Permanent indentation quantifications have been performed using ultrasonic B-scan imaging and have been then compared with direct measurement obtained from resolved optical profilometry. The stiffness measurements method has been used afterwards to estimate loss of rigidity induced by the impact damage. Even if the method provided an estimation of stiffness variation function of damage evolution, the present study indicated that it is less accurate when dealing with BVID. Indeed, the stiffness reduction measurement method have become sensitive at high impact energy levels that cause the damage accumulation prior to sample failure. Furthermore, the comparison of the different experimental methods based on the detectability threshold, has revealed that the ultrasonic permanent indentation (PI) measurement method is very reliable for detecting a change in the surface flatness corresponding to early stages of damage. Furthermore, by estimating accurately the permanent indentation, one can predict the severity of the induced internal damage. A damage threshold between $7.30 \mathrm{~J}$ and $13.45 \mathrm{~J}$ has been reported based on all mentioned results as well as the absorbed energy gap. The proposed PI measurement method has provided a proper approach to evaluate the overall damage tolerance of an impacted composite structure and has been considered as sensitive, accurate and reliable impact induced damage indicator.

The developed experimental approach and the related results correlated with the residual strength estimation can be useful for developing a decision support tool providing the damage tolerance and/or its criticality for an automotive component subjected to low-velocity impact. Indeed, based on the outcomes of the present work, the PI ultrasonic measurement method is considered as a reliable damage indicator that can be helpful for the characterization of the BVID in actual automotive composite parts leading hence to the formulation of damage tolerance criteria.

\section{Acknowledgements}

The authors would like to thank DuPont de Nemours for their support and for providing the material of this study.

\section{Declaration of conflicting interests}

The author(s) declared no potential conflicts of interest with respect to the research, authorship, and/or publication of this article.

\section{Funding}

The author(s) disclosed receipt of the following financial support for the research, authorship, and/or publication of this article: The present work is co-funded by Groupe PSA and ANRT. It is made in the framework of the OpenLab Materials and Processes involving Groupe PSA, Arts et Métiers (ENSAM) and Georgia Tech Lorraine.

\section{ORCID iD}

F Meraghni (D) https://orcid.org/0000-0002-5043-8700

\section{References}

Abrat S (1998) Impact on Composite Structures. Cambridge: Cambridge University Press.

Agrawal S, Singh KK and Sarkar P-K (2013) Impact damage on fibre-reinforced polymer matrix composite A review. Journal of Composite Materials 48 (3): 317-332.

Al-Hajaj Z, Lawrence B, Bougherara H, et al. (2019) Impact properties of a new hybrid composite material made from woven carbon fibres plus flax fibres in an epoxy matrix. Composite Structures 208: 346-356. 
Andrew JJ, Srinivasana SM, Arockiarajanb A, et al. (2019) Parameters influencing the impact response of fiber-reinforced polymer matrix composite materials: A critical review. Composite Structures 224: 111007.

Arif MF (2014) Damage mechanisms in short glass fiber reinforced polyamide-66 under monotonic and fatigue loading: Effect of relative humidity and injection molding induced microstructure. Ecole Nationale Supérieure d'Arts et Metiers.

Arif MF, Meraghni F, Chemisky Y, et al. (2014) In situ damage mechanisms investigation of PA66/GF30 composite: Effect of relative humidity. Composites Part B: Engineering 58: 487-495.

Atas C and Sayman O (2008) An overall view on impact response of woven fabric composite plates. Composite Structures 82(3): 336-345.

Aymerich F and Meili S (2000) Ultrasonic evaluation of matrix damage in impacted composite laminates. Composites Part B: Engineering 31(1): 1-6.

Benaarbia A, Chrysochoos A and Robert G (2014) Influence of relative humidity and loading frequency on the PA6. 6 cyclic thermomechanical behavior: Part I. mechanical and thermal aspects. Polymer Testing 40: 290-298.

Benaarbia A, Chrysochoos A and Robert G (2015) Influence of relative humidity and loading frequency on the PA6. 6 thermomechanical cyclic behavior: Part II. Energy aspects. Polymer Testing 41: 92-98.

Berk B, et al. (2016) An experimental and numerical investigation on low velocity impact behavior of composite plates. Journal of Composite Materials 50(25): 3551-3559.

Budadin ON, Kozelskaya SO, Kaledin VO, et al. (2019) Evaluating impact damage to fabric-based personal armor by infrared NDT. International Journal of Damage Mechanics 28(9): 1393-1417.

Cao M, Gu B and Sun B (2019) Low-velocity impact and residual flexural behaviors of 2. 5-D woven composite under accelerated thermal ageing: Experiment and numerical modelling. International Journal of Damage Mechanics 29(3): 413-434.

Castaings M, Singh D and Viot P (2012) Sizing of impact damages in composite materials using ultrasonic guided waves. NDT \& E International 46: 22-31.

Dalmaz A (2000) Elastic moduli of a $2.5 \mathrm{D} \mathrm{Cf} / \mathrm{SiC}$ composite: Experimental and theoretical estimates. Composites Science and technology 60(6): 913-925.

De Baere I, Jacques S, Van Paepegem W, et al. (2012) Study of the mode I and mode II interlaminar behavior of a carbon fabric reinforced TP. Polymer Testing 31(2): 322-332.

Deniz ME, Karakuzu R and Icten BM (2013) Transverse impact and axial compression behaviors of glass/ epoxy pipes subjected to seawater and impact loading. International Journal of Damage Mechanics 22(7): 1071-1085.

Dhakal HN, Zhang ZY, Bennett N, et al. (2012) Low-velocity impact response of non-woven hemp fibre reinforced unsaturated polyester composites: Influence of impactor geometry and impact velocity. Composite Structures 94(9): 2756-2763.

Dong J, Pomarède P, Chehami L, et al. (2018) Visualization of subsurface damage in woven carbon fiber-reinforced composites using polarization-sensitive terahertz imaging. NDT \& E International 99: 72-79.

Eckel S, Meraghni F, Pomarède P, et al. (2017) Investigation of damage in composites using nondestructive nonlinear acoustic spectroscopy. Expimental Mechanics 57(2): 207-217.

Fang Y, Lin L, Feng H, et al. (2017) Review of the use of air-coupled ultrasonic technologies for nondestructive testing of wood and wood products. Computers and Electronics in Agriculture 137: 79-87.

Gliszczynski A, Kubiak T, Rozylo P, et al. (2018) The response of laminated composite plates and profiles under low-velocity impact load. Composite Structures 207: 1-12.

Greenhalgh E and Hiley M (2003) The assessment of novel materials and processes for the impact tolerant design of stiffened composite aerospace structures. Composites Part A: Applied Science and Manufacturing 34(2): 151-161.

Hufenbach W, Ritschel T, Bohm R, et al. (2006), "Ultrasonic determination of anisotropic damage in fibre and textile reinforced composite materials. In: Conference on damage in composite materials. e-JNondestruct Test (NDT.net).

Hull D and Shi YB (1993) Damage mechanism characterization in composite damage tolerance investigations. Composite Structures 23(2): 99-120. 
Imielińska K, Castaings M, Wojtyra R, et al. (2004) Air-coupled ultrasonic C-scan technique in impact response testing of carbon fibre and hybrid: glass, carbon and kevlar/epoxy composites. Journal of Materials Processing Technology 157-158: 513-522.

Kara M and Muhammed K (2017) Effects of the number of fatigue cycles on the impact behavior of glass fi ber/epoxy composite tubes. Composites Part B: Engineering 123: 55-63.

Kim J and Sham M (2000) Impact and delamination failure of woven-fabric composites. Composites Science and Technology 60(5): 745-761.

Liang S, Guillaumat L and Gning P (2015) Impact behaviour of flax/epoxy composite plates. International Journal of Impact Engineering 80: 56-64.

Maier A, Schmidt R, Oswald-Tranta B, et al. (2014) Non-Destructive thermography analysis of impact damage on large-scale CFRP automotive parts. Materials (Basel, Switzerland) 7(1): 413-429.

Marguères P and Meraghni F (2013) Damage induced anisotropy and stiffness reduction evaluation in composite materials using ultrasonic wave transmission. Composites Part A: Applied Science and Manufacturing 45: 134-144.

Margueres P, Meraghni F and Benzeggagh ML (2000) Comparison of stiffness measurements and damage investigation techniques for a fatigued and post-impact fatigued GFRP composite obtained by RTM process. Composites Part A: Applied Science and Manufacturing 31(2): 151-163.

Nachtane M, Tarfaoui M, Sassi S, et al. (2019) An investigation of hygrothermal aging effects on high strain rate behaviour of adhesively bonded composite joints. Composites Part B: Engineering 172: 111-120.

Nash NH, Young TM, Mcgrail PT, et al. (2015) Inclusion of a thermoplastic phase to improve impact and post-impact performances of carbon fibre reinforced thermosetting composites - A review. Materials \& Design 85: 582-597.

Osada T, Nakai A and Hamada H (2003) Initial fracture of satin woven fabric composites. Composite Structures 61(4): 333-339.

Polimeno U and Meo M (2009) Detecting barely visible impact damage detection on aircraft composites structures. Composite Structures 91(4): 398-402.

Pomarède P (2018) Damage detection PA66/6|Glass woven fabric composite material using ultrasonic techniques towards durability prediction of automotive parts. Ecole Nationale Supérieure d'Arts et Métiers.

Pomarède P, Meraghni F, Peltier L, et al. (2018) Damage evaluation in woven glass reinforced polyamide 6. 6/6 composites using ultrasound phase-shift analysis and X-ray tomography. Journal of Nondestructive Evaluation 37(12).

Praud F (2018) Multi-scale modelling of thermoplastic-based woven composites, cyclic and time-dependent behaviour. Ecole Nationale Supérieure d'Arts et Métiers.

Praud F, et al. (2017) Modélisation multi-échelle des composites tissés à matrice thermoplastique sous chargements cycliques non proportionnels. JNC20. Journée nationale sur les composites.

Ravikara A, Venkataramanaiah NK, Bhat M, et al. (2006) Detection and evaluation of impact damage in CFRP laminates using ultrasound C-scan and IR thermography. In: National seminar on non-destructive evaluation.

Shah SZH, Karuppanan S, Megat-Yuso PSM, et al. (2019) Impact resistance and damage tolerance of fiber reinforced composites: A review. vol. 217, pp.100-121.

Sierakowski RL and Newaz GM (1995) Damage Tolerance in Advanced Composites. 1st ed. Pennsylvania: Lancaster.

Sassi S, Tarfaoui M, Nachtane M, et al. (2019) Strain rate effects on the dynamic compressive response and the failure behavior of polyester matrix. Composites Part B: Engineering 174.

Tarfaoui M and Nachtane M (2019) Can a three-dimensional composite really provide better mechanical performance compared to two-dimensional composite under compressive loading? Journal of Reinforced Plastics and Composites 38(2): 49-61.

Tarfaoui M, Nachtane M and Moumen AE (2019) Energy dissipation of stitched and unstitched woven composite materials during dynamic compression test. Composites Part B: Engineering 167: 487-496.

Weng J, Wen W and Zhang H (2017) Study on low-velocity impact and residual strength at high temperatures of composite laminates. Journal of Aerospace Engineering 233(3): 1106-1123. 